\title{
Unifying subject agreement across clause types in Estonian ${ }^{*}$
}

\author{
Mark Norris
}

\begin{abstract}
Estonian negated indicative clauses show no agreement, whereas Estonian negated imperative clauses show agreement twice: once on the main verb and once on the negation word ära. This contrasts with affirmative clauses, where agreement appears only once. I propose a unified syntax for agreement across these clausal types, arguing that the there is one head which bears a $\phi$-feature probe in all Estonian sentences. There is no agreement in negated indicatives because this head has only one suitable vocabulary item in this context: ei. Doubled agreement arises due to a rule of postsyntactic Feature Copying in imperative contexts. I argue that this analysis is superior to an analysis making use of multiple $\phi$-feature probes in the syntax, as such analyses struggle to account for the optionality of doubling in first-person plural contexts. The proposed analysis makes predictions about the kinds of marking possible in negated imperatives, which appear to be borne out in related Uralic languages. This investigation supports a view of the morphosyntax of agreement whereby the syntax and morphology of agreement overlap but do not coincide.
\end{abstract}

Keywords: agreement, Estonian, imperatives, negation

\section{Introduction}

In the canonical case of subject-verb agreement, there is one instance of subject agreement in person and number (hereafter: $\phi$-features) on the finite verb. This is shown for Estonian in (1) and (2). ${ }^{1}$

\footnotetext{
I started thinking about these patterns in collaboration with Anie Thompson in 2013, and her contributions to the project are gratefully acknowledged. Thanks are also due to Claire Halpert, Jorge Hankamer, Boris Harizanov, Ruth Kramer, Ethan Poole, Virve Vihman, and audiences at UCSC's Morphology Reading Group, the 88th Annual Meeting of the Linguistic Society of America, and the Workshop on Syntactic Structures of Uralic Languages at the XII International Congress for Finno-Ugric Studies in Oulu, Finland. Thanks to András Bárány for technical support. Thanks to two anonymous reviewers, whose critique and suggestions have improved this paper in terms of argumentation and rhetorical flow. Finally, I thank the following speakers of Estonian for discussing their language with me: Leelo Kask, Kärt Lazić, and Katrin Jänese. I am responsible for any remaining errors.

Glossing abbreviations are as follows: 1 first person, 2 second person, 3 third person, ACC accusative case, ADE adessive case, CNG connegative, COND conditional, DA.INF da-infinitive, DU dual number, FRQ frequentative, HOR hortative, IMP imperative, INE inessive case, NEG negation, PAR partitive case, PASS passive/impersonal, PCPL participle, PL plural number, PST past tense, sG singular number.

Some examples come from online resources for the Estonian language. The first (BALANCED) is a balanced literary corpus containing equal parts fiction, journalism, and academic writing. The second (EKss) is an online dictionary of standard Estonian (Eesti keele seletav sonaraamat). Both are available online at http://www. keeleveeb.ee/. 
(1) Sa vaata-d filmi.

you watch-2sG movie.PAR

'You are watching a movie.'

(2) Te vaata-te filmi.

you.PL watch-2PL movie.PAR

'You (pl/formal) are watching a movie.'

In (1), the verb bears the suffix $-d$ indicating agreement with a second-person singular subject, and in (2) the verb bears -te, indicating agreement with a second-person plural subject. Under standard Minimalist conceptions, this kind of agreement is formalized as an Agree relation (between the subject and the verb, loosely speaking) in the syntax correlating with one agreement marker in the morphology.

However, this one-to-one relationship between syntactic agreement relation and morphological exponence of agreement does not always obtain in Estonian. In addition to contexts where there is one morphological exponent of agreement, there are situations in Estonian where there is no agreement and situations where agreement is doubled. These complex patterns require a closer look at the relationship between the syntax and morphology of agreement in the language. In this paper, I investigate and analyze the agreement patterns in negated imperatives, which show doubling, and negated indicatives, where agreement disappears, and I argue that the most successful analysis is one in which syntactic agreement (i.e., the Agree relation) and morphological agreement (i.e., the presence of agreement markers) overlap but are not isomorphic. Under the analysis I propose, the differing morphological situations disguise a system that is syntactically uniform. Before getting to the analysis, I present the morphological patterns in more detail.

Like indicative clauses, affirmative imperative clauses also exhibit one instance of subject-verb agreement. The paradigm of agreement markers for imperatives is different than the paradigm used in indicatives, as is visible in (3) and (4).
Vaata
filmi!
watch.IMP.2SG movie.PAR
'Watch a movie!'

Vaada-ke filmi!
watch-IMP.2PL movie.PAR
'Watch a movie!'

$(4)$

The second-person singular imperative (in (3)) has no ending (I represent this in the table as a null morpheme $-\emptyset$ ), and the second-person plural (in (4)) uses the morpheme $-g e / k e^{2}$

Full paradigms for indicative and imperative clauses are presented in Table 1 on the following page. ${ }^{3}$ Examples such as affirmative clauses in Estonian are the canonical case, a one-to-one correspondence between syntactic and morphological agreement.

The situations where the agreement patterns diverge are found in negated clauses. Negated indicative clauses exhibit no morphological agreement. In the present tense, the main verb appears in a form that resembles an inflected stem without the inflection. This

\footnotetext{
2 The choice between -ge and -ke is part of Estonian's complex morphophonological system of stem alternation known as gradation. It is largely irrelevant to the issues I address here, so I will not discuss it
} 


\begin{tabular}{ccc}
\hline \multicolumn{3}{c}{ InDICATIVE } \\
& SG & PL \\
\hline 1 & $-n$ & $-m e$ \\
2 & $-d$ & $-t e$ \\
3 & $-b /-s$ & $-v a d /-d$ \\
\hline
\end{tabular}

\begin{tabular}{ccc}
\hline \multicolumn{3}{c}{ IMPERATIVE } \\
& SG & PL \\
\hline 1 & $-g u / k u$ & $-m e$ \\
& & $-g e m / k e m$ \\
2 & $-\emptyset$ & $-g e / k e$ \\
3 & $-g u / k u$ & $-g u / k u$ \\
\hline
\end{tabular}

Table 1: Estonian agreement paradigms: indicative (left) and imperative (right)

form is sometimes called the CONNEGATIVE form, as it is a verb form that appears with negation. Examples are given in (5).
a. Sa ei vaata $\left.{ }^{*}-d\right)$ filmi.
You NEG watch-2sG movie.PAR
'You are not watching a/the movie.'
b. Te ei vaata $\left.{ }^{*}-t e\right)$ filmi.
You.PL NEG watch-2PL movie.PAR
'You (PL/formal) are not watching a/the movie.'

As shown in (5), negated indicative clauses with overt agreement morphemes are ungrammatical.

In contrast, negated imperatives exhibit agreement twice: once on the main verb and once on the word $\ddot{a} r a$, which is traditionally identified as an imperative negative auxiliary. ${ }^{4}$
a. Ära vaata filmi!
'Don't watch a/the movie!'
IMP.NEG.2sG watch.IMP.2sG movie.PAR
b. $\ddot{A r} r^{*}(-g e) \quad v a a d a^{*}(-k e)$ filmi!
IMP.NEG-2PL watch-IMP.2PL movie.PAR
'Don't watch a/the movie!'

The imperative negative auxiliary's agreement paradigm is clearly the imperative paradigm; compare the forms of ära shown in Table 2 with the forms in Table 1.

Thus, both ära and the main verb morphologically express imperativity and agreement. I refer to this pattern as Doubling. There are thus three types of exponence in Estonian: standard (single) agreement, no agreement, and doubling.

I argue that these three patterns of exponence arise from a unified syntax of agreement: in Estonian clauses, there is always exactly one head bearing $[u \phi]$. I propose this head is the polarity head $\mathrm{Pol}^{0}$. This straightforwardly predicts one instance of agreement, as in affirmative clauses. The patterns of doubled agreement and no agreement emerge

in detail. I assume for concreteness that the alternation amounts to contextual allomorphy determined by particular verbal roots, but see Blevins (2007) for further discussion.

3 The $-g u / k u$ forms are not always included as part of the imperative paradigm (see, e.g., Erelt 2003), as that is the ending associated with the jussive. I have included them in the paradigm in the interest of completeness.

4 This pattern is also observable in negated jussive clauses (see, e.g., Tamm 2015, 408-410). I focus here on imperatives, but the patterns seen in jussive clauses are fully compatible with my analysis, as far as I can tell. 


\begin{tabular}{ccc}
\hline & SG & PL \\
\hline 1 & $\ddot{a} r-g u$ & $\ddot{a} r-m e$ \\
& & $\ddot{a} r-g e m$ \\
2 & $\ddot{a} r a$ & $\ddot{a} r-g e$ \\
3 & $\ddot{a} r-g u$ & $\ddot{a} r-g u$ \\
\hline
\end{tabular}

Table 2: Agreement paradigm for the imperative negative auxiliary ära

due to the morphology of Estonian, in ways that are made precise below. The end result is a system with a unified syntax of agreement across clausal types but a complex mapping between the syntax of agreement and its morphological exponence. This is consistent with a theory where morphological and syntactic agreement overlap but are not isomorphic (Chung 2013). This analysis also has support from patterns seen in other Uralic languages: while doubling occurs in some languages, the most common pattern is for imperative-marking and agreement to appear only on negation, consistent with the idea that doubling is idiosyncratic morphology rather than evidence of a syntactic relation.

An alternative viewpoint that I consider is that every instance of morphological agreement corresponds to an agreement relationship in syntax, and vice versa. This alternative view is tacitly assumed in some research on agreement, especially in analyses of multiple agreement in the clausal domain by Baker and Willie (2010) and Carstens (2001), and Henderson (2006). For Estonian, negated indicatives would have no agreement-neither syntactic, nor morphological - and negated imperatives would have two instances of syntactic agreement that correspond to two morphological exponents of agreement. While this simplifies the mapping between the syntax and morphology of agreement, it precludes the possibility of a unified syntax of agreement across clause types in Estonian. I believe it is desirable to seek a unified syntax of agreement in the language, as it extends more readily to systems in other Uralic languages (and beyond). More strongly, I show that it is difficult for this type of analysis to generate all of the correct results in Estonian, casting doubt on its general viability in the language.

I begin by providing additional background information in Section 2 before proposing my analysis in Section 3. I consider and reject the alternative analysis mentioned above in Section 4. In Section 5, I consider how my analysis helps us understand the patterns of agreement and imperative-marking in negated imperatives in other Uralic languages, and I discuss a type of unattested imperative-marking within Uralic that is predicted to be nonexistent by my analysis. I offer some directions for future research in Section 6 .

\section{Background Assumptions}

This analysis is formalized within a Minimalist approach to syntax (Chomsky 1995, et seq.) combined with the proposals of Distributed Morphology (Halle 1990; Halle and Marantz 1993). In this framework, the syntax manipulates sets of abstract morphological features with no phonological content. Morphological forms are supplied after syntactic operations at a step known as Vocabulary Insertion, which is taken to occur as part of the interface responsible for phonetic and phonological form $(\mathrm{PF})$. Importantly, within this approach, 
there are postsyntactic morphological operations that can alter the syntactic representation before Vocabulary Insertion takes place (see, e.g., Arregi and Nevins 2012; Embick 2010; Harley and Noyer 1999). This system is schematized below.

(7)

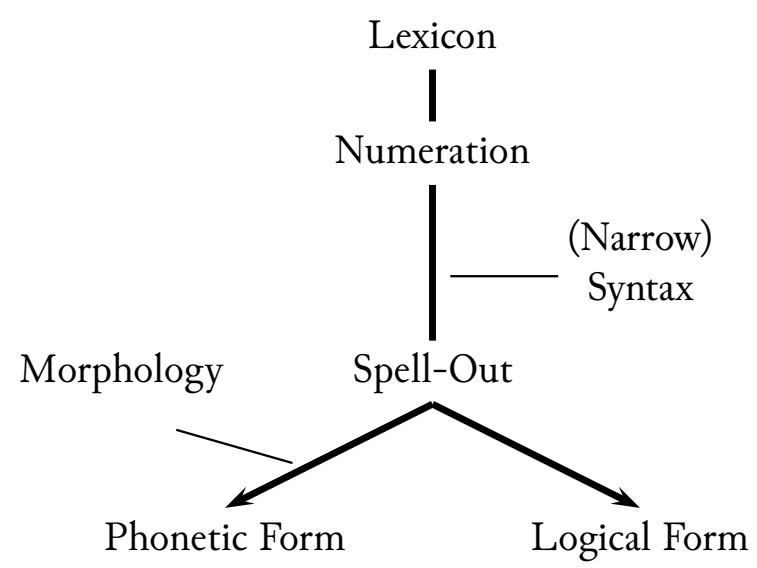

One particular syntactic operation figures prominently in the analysis. It is commonly known as Agree (Chomsky 2000, 2001; Preminger 2014, a.o.). The formalization of Agree is subject to some variation, but the core aspects are fairly consistent. The formalization I adopt is given in (8).

(8) Agree:

a. A syntactic head with an unvalued feature or set of features [ $u$ FEAT] (the PROBE) searches within its c-command domain for a node with a corresponding valued feature or feature set (the GOAL).

b. If the probe finds a suitable goal, the goal's relevant features are copied to the probe, and Agree is complete.

c. If the probe fails to find a suitable goal, Agree fails, and no values are supplied to the probe. ${ }^{5}$

In the situations considered here, the probe has a set of unvalued $\phi$-features $([u \phi])$, and it finds a suitable set of $\phi$-features on the subject DP, which I assume (for concreteness) to be generated in Spec,vP. Those $\phi$-features are copied to the probe and they are canonically realized (at PF) as an agreement marker. In what follows, the precise question that I investigate is how closely morphological agreement tracks syntactic Agree.

\subsection{Basic proposals regarding Estonian clause structure}

While there are no significant proposals regarding the functional structure of the Estonian IP within a generative framework, there are a number of proposals for Finnish, and they more or less converge on the same structure (Brattico and Huhmarniemi 2006; Brattico et al. 2014; Holmberg and Nikanne 2002; Holmberg et al. 1993; Huhmarniemi 2012; Koskinen 1998; Mitchell 1991). A synthesis of these views is presented below.

\footnotetext{
5 Under some formalizations of the operation, failure of Agree leads to ungrammaticality. See Preminger (2014) for a thorough rebuttal against these kinds of approaches.
} 
(9)

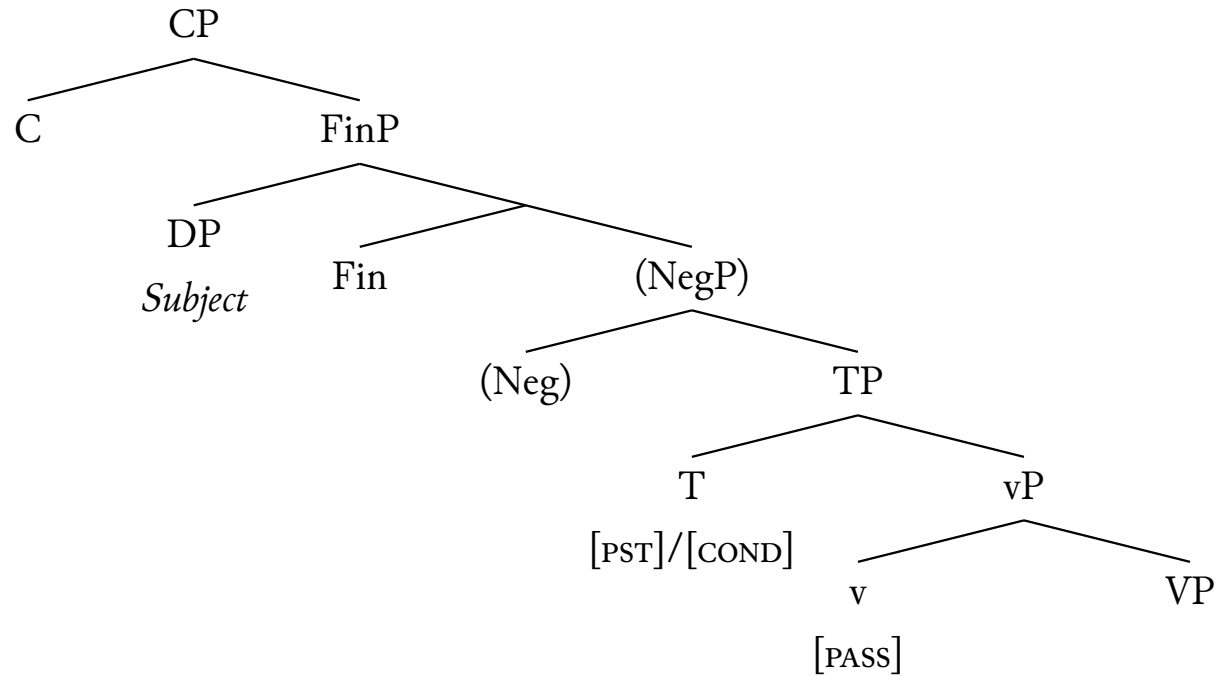

Two particular aspects of this proposal are worth mentioning at the moment. First, Fin (ite $)^{0}$ is the head that is responsible for finiteness, as visible by subject-verb agreement. In addition, the neutral position of the subject (or more properly, topic) is taken to be Spec,FinP. Second, if Negation is present, it is in between Fin $^{0}$ and $\mathrm{T}^{0}$. This reflects the fact that, in negated sentences, negation bears agreement, but tense is still reflected only on the main verb. This is visible for Finnish in (10) and (11).

$$
\begin{aligned}
& \text { pubu-n / pubu-i-n } \\
& \text { speak-1sG speak-PST-1sG } \\
& \text { 'I speak' 'I spoke' } \\
& \begin{array}{lll}
e-n \quad \text { pubu } & \text { / } & e-n \quad p u b u-n u t \\
\text { NEG-1sG speak } & & \text { NEG-1sG speak-PST.PCPL(SG) }
\end{array} \\
& \text { 'I don't speak' 'I didn't speak' }
\end{aligned}
$$

The examples in (10) establish that, in affirmative clauses, the verb reflects both tense and agreement. In the negated sentences in (11), the expression of agreement and tense is split, with negation bearing agreement and the main verb expressing the tense of the clause.

Turning to Estonian, the facts regarding negation and tense are the same: the main verb bears tense in negated clauses, and negation does not (see (12) and (13)).

$$
\begin{aligned}
& \text { Ma ei maga. } \\
& \text { 1sG NEG sleep } \\
& \text { 'I don't sleep.' }
\end{aligned}
$$

$$
\begin{aligned}
& \text { Ma ei maga-nud. } \\
& \text { 1sG NEG sleep-PST.PCPL } \\
& \text { 'I didn't sleep.' }
\end{aligned}
$$

These facts follow the same pattern as Finnish with respect to tense-marking: compare maga 'sleep' in (12) to maganud 'sleep.PST.PCPL' in (13). As in Finnish, the main verb does not bear agreement in negated indicatives in Estonian, whether past or present. I take this as evidence that the $\phi$-feature probe in Estonian clauses is also higher than negation (as in Finnish), as the introduction of negation blocks $\phi$-feature agreement on the main verb. However, unlike negation in Finnish, Estonian indicative negation does not show any agreement: it is always ei (see also (5)). I set this aside for the moment, returning to an analysis of indicative negation in Section 3.2.

Imperative clauses are not discussed in detail in much of the literature on Finnic clausal architecture; some important exceptions are Brattico et al. (2014), Mitchell (1991), 
and Nelson (1998). Nelson (1998) proposes that the morphosyntactic feature(s) unique to imperative clauses are lower (on $\mathrm{T}^{0}$, below negation and Fin ${ }^{0}$ ), while Brattico et al. (2014) and Mitchell (1991) propose that the morphosyntactic features unique to imperative clauses are located on $\mathrm{C}^{0}$, which is above negation and finiteness (see also Han 1999; Rivero and Terzi 1995). I propose the same for Estonian, i.e., that morphosyntactic imperative features are located on $C^{0}$, but I will come back to Nelson's (1998) proposal in Section 5.

Taking these proposals together, the structure of the Estonian clause that serves as the basis for my analysis is presented in (14).

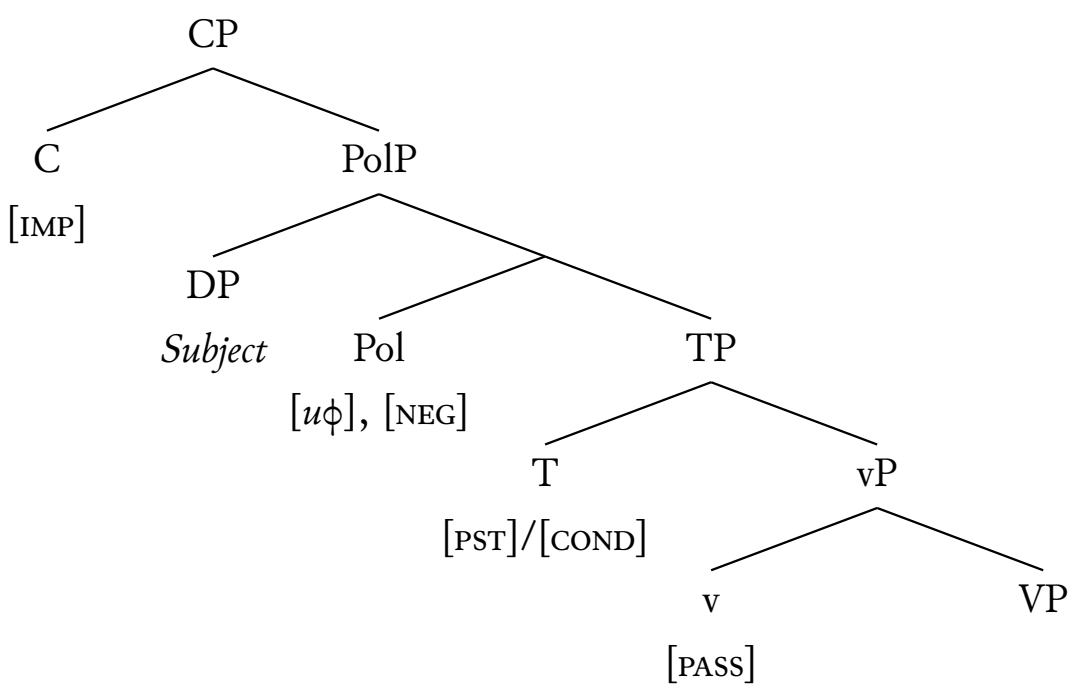

Some aspects of the structure deserve comment. First, though I have not discussed it here, I assume that $\mathrm{v}^{0}$ is the location of the impersonal/passive suffix. Second, I have collapsed $\mathrm{Neg}^{0}$ and $\mathrm{Fin}^{0}$ into one head: $\mathrm{Pol}^{0}$. As far as I can tell, $\mathrm{Neg}^{0}$ serves no purpose other than the introduction of the negation head, which always moves to Fin ${ }^{0}$. Instead of this, I propose a head $\mathrm{Pol}^{0}$ (for polarity) that comes in two flavors: one with [NEG] and one without. $\mathrm{Pol}_{[\mathrm{NEG}]}{ }^{0}$ spells out as negation, and plain $\mathrm{Pol}^{0}$ spells out as $\phi$-feature agreement. The proposals I make in what follows are compatible with an analysis that does not collapse Fin $^{0}$ and $\mathrm{Neg}^{0}$, but I will do so in the interest of simplicity. This means that whatever information besides $[u \phi]$ is assumed to be present on $\mathrm{Fin}^{0}$ must be present on $\mathrm{Pol}^{0}$ instead, although the discussion that follows focuses only on $[u \phi]$.

Within this structure, I assume that the verb undergoes head movement up the clausal spine. I assume it moves as high as $\mathrm{T}^{0}$ in all clauses, as has been proposed for Finnish (Holmberg and Nikanne 2002, a.o.). In affirmative clauses, the verb continues to $\mathrm{Pol}^{0}$. In negated clauses, head movement to $\mathrm{Pol}_{[\mathrm{NEG}]}^{0}$ is blocked, and the verb stays in $\mathrm{T}^{0}$. This is shown for affirmative clauses in (15) and negated clauses in (16).

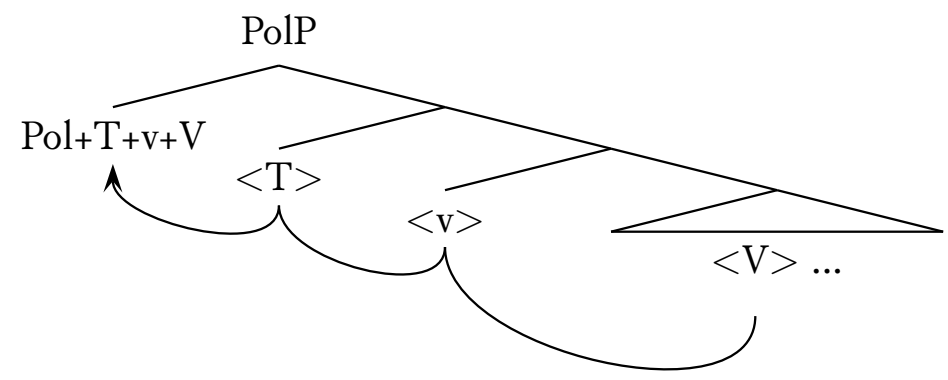




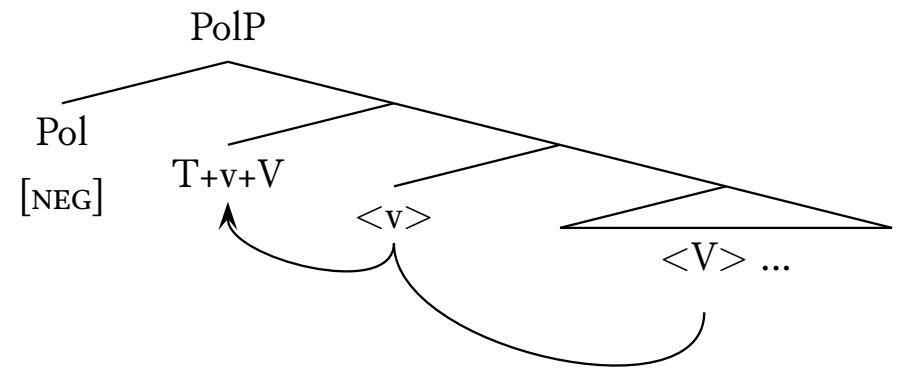

The interaction of $\mathrm{Pol}^{0}$ and $\mathrm{C}_{[\mathrm{IMP}]}^{0}$ is part of the core of the analysis, which is discussed in the next section. Let us turn to it now.

\section{$3 \quad \ddot{r} r a$ as a conglomeration of negation and imperativity}

As we have seen, negated imperative clauses in Estonian are not formed with $e i$, but with a special negative auxiliary $\ddot{a r a} .^{6}$ Unlike Estonian $e i$, ära morphologically agrees with the subject, and the set of agreement markers that appear is the same imperative paradigm as that which appears on the main verb in an affirmative imperative. ${ }^{7}$ Additional examples are in (17).

$$
\begin{aligned}
& \text { a. Är-ge kõndi-ge muru-l! } \\
& \text { IMP.NEG-2PL walk-IMP.2PL grass-ADE } \\
& \text { 'Don't walk on the grass!' } \\
& \text { b. Ära kõnni muru-l! } \\
& \text { IMP.NEG.2sG walk.IMP.2sG grass-ADE } \\
& \text { 'Don't walk on the grass!' }
\end{aligned}
$$

(Erelt et al. 1993, 155)

Recall as well that the main verb bears imperative agreement in negated imperatives (e.g., kondi-ge 'walk-IMP.2PL' in (17a)). This means that agreement and imperativity are real-

\footnotetext{
6 An anonymous reviewer asks about the etymology of $\ddot{a} r a$ and $e i$, and in particular, whether their relationship can be illuminated by historical evidence. I have not found anything particularly interesting as of yet. The etymological dictionary of Estonian (Eesti etümoloogiasõnaraamat, available online at http://www.eki.ee/dict/ety/) collapses the entries for ära and ei into one entry. The entry provides the cognate forms in a variety of languages, including both the indicative and imperative negative auxiliary. Some of these forms are given in Section 5 of the present article. However, I will refrain from speculating and simply note that this is a question worth investigating. Thanks to Anne Tamm for helpful discussion of this issue.

7 I will continue to refer to imperative agreement as agreement with the subject, and I will represent it formally as such. However, the source of this agreement is a matter of some debate within the literature. Kiparsky (2001) proposes that agreement in imperatives is not the same as agreement in non-imperative clauses in Finnish (pp. 335-6), and Miljan and Cann (2013) claim something similar for Estonian, proposing the agreement is "not syntactic but pragmatic" (p. 360). I note first that the observations Kiparsky and Miljan \& Cann make do not preclude a syntactic account: see, e.g., Zanuttini (2008) and Zanuttini et al. (2012). However, even if the pragmatic approach is superior, the choice between the pragmatic account and the syntactic account is ultimately about the proper controller of agreement, whereas the phenomenon I am investigating is about the exponence of agreement. It seems to me that the puzzle of multiple agreement exponence in negated imperatives remains even if the controller is pragmatic in nature. Thus, in what follows, I assume a syntactic approach for concreteness.
} 
ized twice: once on ära and once on the main verb. ${ }^{8}$ It is ungrammatical to leave either agreement exponent out, whether on negation (as in (18a)) or on the main verb (as in $(18 b))$.
a. * $\ddot{A r a}$ söö-ge seda kooki! IMP.NEG eat-IMP.2PL that.PAR cake.PAR
Intended: 'Don't eat that cake!'
b. * $\ddot{A} r-g e \quad$ söo seda kooki! IMP.NEG-2PL eat.IMP that.PAR cake.PAR
Intended: 'Don't eat that cake!'

However, there is one exception to the general pattern of obligatory imperative agreement doubling in Estonian negated imperatives. For [1 $\mathrm{PL}]$ imperatives using the ending -me, agreement on the main verb is optional. ${ }^{9}$ When agreement does not appear on the main verb, the main verb instead surfaces in the ordinary present connegative form. This is illustrated in (19) and (20).

$$
\begin{aligned}
& \ddot{A r} \text {-me vaata(-me) filmi! } \\
& \text { IMP.NEG-1PL watch(-1PL) film.PAR } \\
& \text { 'Let's not watch a/the movie!' } \\
& \text { är-me tee(-me) } \\
& \text { IMP.NEG-1PL do(-1PL) } \\
& \text { 'Let's not do' }
\end{aligned}
$$

As Tamm (2015) shows, both forms - with doubling and without it-exist in modern spoken and written registers of varying levels of formality in the modern language, though she suggests that the standardization of the non-agreeing form is a somewhat recent development.

There are two primary questions that I address with my analysis. First, why are both negation and the main verb inflected for imperative features? Assuming that imperative morphology is connected to a morphosyntactic feature (e.g., [IMP]), it is worth considering which of the imperative inflections (i.e., that on negation or that on the main verb) is connected to this feature. Second, what is the source of the doubled $\phi$-feature marking, and how can we formalize it such that it can be optional in the case of [1PL] agreement?

In response to the first question, I argue that the imperative marking on negation is connected to "true" (i.e., syntactic) imperativity. In response to the second question, I argue that agreement on $\ddot{r} r$, i.e., negation, is the reflex of an Agree relationship. Thus, the imperative negator is directly connected to both syntactic features, [IMP] and $\phi$-features.

\footnotetext{
8 It is difficult to know whether the main verb is inflecting for person and number in the context of second-person singular subjects, as it is in a form that is homophonous with the present connegative form for nearly every verb in the language. The only verb for which this is not true is minema 'go', where the 2sG imperative form is mine but the present connegative form is lähe. Because of this, I believe the verb is bearing agreement in this context.

9 Another ending is possible for [1PL] imperatives: -gem/-kem. As Tamm (2015) observes, there is a register difference between -me and -gem, such that the -gem form is quite formal. Unlike -me, $-\mathrm{gem}$ obligatorily doubles in negated imperatives. I assume this difference can be attributed to a morphosyntactic feature related to formality or to different dialects, which is independently necessary in order to capture the fact that $-m e$ and $-\mathrm{gem}$ are both possible exponents for [1 $\mathrm{PL}]$ in imperatives.
} 
In contrast, I propose that the agreement and imperative-marking on the main verb is the result of a different operation. Furthermore, I argue that the optionality of [1PL] doubling suggests that this operation is morphological rather than syntactic in nature. I propose that it is an instance of Feature Copying (Kramer 2010; Norris 2014), an idiosyncratic rule of Estonian triggered by the presence [IMP] and [NEG] on the same head.

The primary focus of this section is to lay out my analysis and show how it works. The two sections following this one show in more detail why the analysis I propose is preferable. In Section 4, I consider an alternative that is more along the lines of the work that proposes multiple $\phi$-feature probes (e.g., Baker and Willie 2010; Carstens 2001; Henderson 2006), and I show that it is less plausible than the analysis I advocate for. Then in Section 5, I show that my analysis makes interesting predictions with respect to negated imperatives in the Uralic family, lending further support to the analysis proposed in this section.

\subsection{Analysis: morphology and syntax of negated imperatives}

The analysis is broken up into two parts. Beginning with the assumption that imperative clauses are connected to a feature (or set of features) in the syntax, I propose that Estonian has a $\mathrm{C}^{0}$ with an imperative feature, which I call [IMP] for concreteness. In an affirmative imperative clause, the finite verb is high, indicated by the fact that it can readily appear before the subject when the subject is overt.

$$
\begin{aligned}
& \text { (Sa) kasta lilli! } \\
& \text { you water.IMP.2sG flower.PL.PAR } \\
& \text { 'Water (some) flowers!' } \\
& \text { Kasta SINA lilli! } \\
& \text { water.IMP.2sG you flower.PL.PAR } \\
& \text { 'YOU water (some) flowers!' }
\end{aligned}
$$

In (21), the pronoun $s a$ 'you' can appear before the verb. Importantly, the subject pronoun can also appear after the verb, as in (22). ${ }^{10}$ I attribute this to head movement: the verb moves all the way to $\mathrm{C}^{0}$ in imperative clauses. For concreteness, I suggest the variable positioning of the subject (before or after the verb) is due to an optional movement of the subject to Spec,CP, though the position of the subject will not affect the analysis I propose. ${ }^{11}$ If the subject remains in Spec,PolP, then it is post-verbal. ${ }^{12}$

Turning to negated imperatives, recall that head movement of the verb stops at $\mathrm{T}^{0}$ when $\mathrm{Pol}_{[\mathrm{NEG}]} 0$ is present. This accounts for the fact that the verb inflects for tense but not

\footnotetext{
10 The form, sina or $s a$, does not affect the possible positions, as far as I have been able to tell.

11 Based on the research conducted on Finnish, I believe this movement to Spec,CP is likely driven by information-structural considerations. For example, Holmberg and Nikanne (2002) note that Spec,CP is generally reserved for contrastive topics. I have not yet uncovered any significant contrasts in the interpretation of imperatives with preverbal or postverbal subjects in fieldwork, though a reviewer notes that postverbal subjects in imperatives are normally interpreted as contrastive, suggesting the default position for the subject in an imperative is preverbal. I must leave this issue unresolved here, although I note that the exact positioning of the subject is tangential to the point that I am trying to make about agreement exponence.

12 In Finnish, the imperative subject, when present, must be post-verbal. I have no explanation for why Finnish and Estonian differ in this respect.
} 
agreement in negated clauses. This also precludes the verb from reaching $\mathrm{C}^{0}$ as it does in affirmative imperatives. However, $\mathrm{Pol}^{0}$ is able to move to $\mathrm{C}^{0}$ as normal- it just does not contain the verbal complex. This movement yields the complex head in (23). ${ }^{13}$

(23)

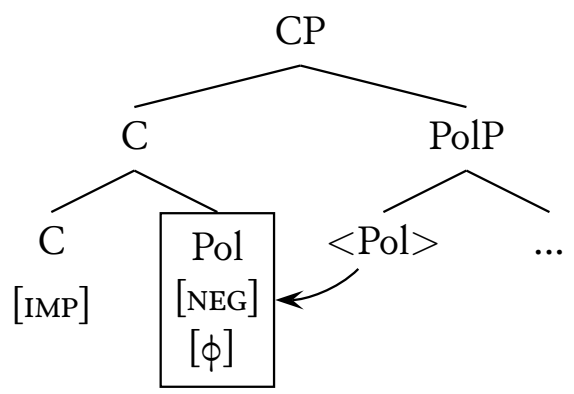

Thus, the only difference between negated imperatives and affirmative imperatives is whether or not the verbal complex raises to $\mathrm{Pol}^{0}$. In either case, $\mathrm{Pol}^{0}$ always raises to $\mathrm{C}_{[\mathrm{IMP}]}{ }^{0}$.

As indicated in (23), $\mathrm{Pol}_{[\mathrm{NEG}]}{ }^{0}$ has already established Agree with the subject DP by the time it raises to $C^{0}$, and the subject's $\phi$-features, along with negation and imperativity, now form a complex head in $\mathrm{C}^{0}$. This is the essence of the special negative imperative auxiliary ära: it is the morphological form supplied to the complex $\mathrm{C}^{0}$ head, expressing negation, imperativity, and the subject's $\phi$-features. Imperativity is visible at least in the agreement paradigm used, which is the language's imperative agreement paradigm. It is reasonable to suggest ära reflects negation given (i) its restriction to negative imperatives, and (ii) the fact that no other sentential negation is possible. ${ }^{14}$

At this point, the representation is sent to the $\mathrm{PF}$ interface where it can be interpreted by the morphology. To begin, I propose that $\mathrm{C}_{[\mathrm{MMP}]}{ }^{0}$ and $\mathrm{Pol}_{[\mathrm{NEG}]}{ }^{0}$ undergo Fusion (Halle 1990; Halle and Marantz 1993), which takes two terminal nodes which are sisters and combines their feature bundles to form a single node as represented in (24). The new fused head is ultimately spelled out as ära.
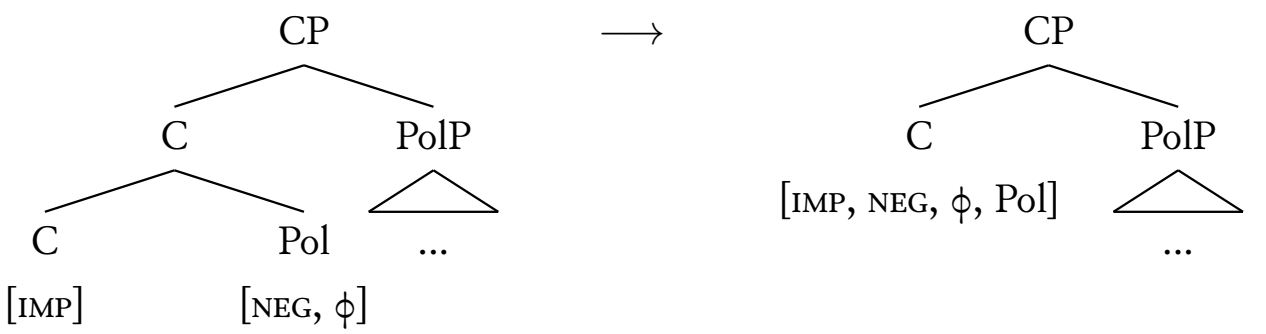

\footnotetext{
13 An issue that I do not address here is how such a complex head would be interpreted, especially as far as scope is concerned. This issue could be avoided under an account where head movement does not occur until PF (e.g., Schoorlemmer and Temmerman 2012) or where ära is not derived via Head Movement, but Spanning (Merchant 2015; Svenonius 2012). I will not attempt to construct such an account here.

14 However, I note here that the alternative analysis that I consider in Section 4 does not adopt this characterization for ära.
} 
(25) Imperative Negative Auxiliary Vocabulary Items (simplified): ${ }^{15}$
a. C, [IMP, NEG, 2sG] $\leftrightarrow$ ära
b. $\quad$ C, [IMP, NEG, 1PL] $\leftrightarrow$ ärme
c. $\quad$ C, [IMP, NEG, 2PL] $\leftrightarrow$ ärge
d. C, [IMP, NEG] $\leftrightarrow \ddot{a r g u}$

Thus, under this analysis, the term "negative imperative auxiliary" refers to a $\mathrm{C}^{0}$ that contains $\phi$-features, the imperative feature [IMP], and the negation feature [NEG].

Turning now to the main verb, recall that it expresses imperative agreement as well in negated imperatives. Thus, as far as the morphology is concerned, the main verb needs to acquire the imperative feature [IMP] as well as the subject's $\phi$-features. Since those features are bundled up in $\mathrm{C}^{0}$, we have to say something more. It will not do to propose a second $\phi$-feature probe on a lower head, e.g., $\mathrm{T}^{0}$. We have already seen evidence against such a proposal from negated indicatives, where the main verb bears tense but no agreement. If $\mathrm{T}^{0}$ were a probe, this would be unexpected. Thus, while two $\phi$-feature probes might simplify negated imperatives, they complicate negated indicatives, as well as affirmative clauses in general.

I propose instead that doubling is the result of a morphological rule of Feature Copying, triggered by $\mathrm{C}^{0}$ specified as [IMP, NEG]. First, an Agr node is adjoined to $\mathrm{T}^{0}$, and subsequently, $\mathrm{C}^{0}$ 's features are copied onto that Agr node. This is represented schematically in (26), where the dashed branch indicates a slight abbreviation in the structure.

(26)

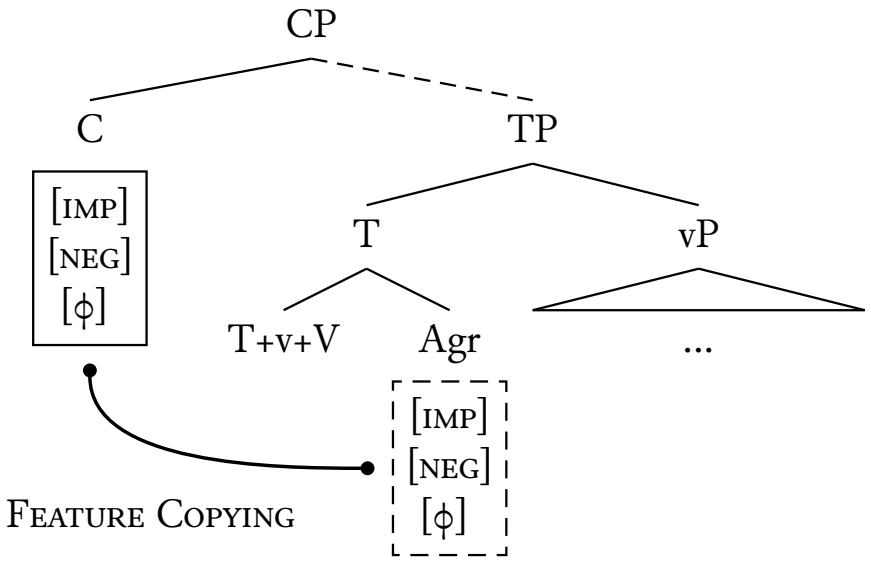

This copies all of the features of $\mathrm{C}^{0}$, including [NEG], which is essentially ignored at Vocabulary Insertion. I do this in the interest of simplicity: it is simpler to have $\mathrm{C}^{0}$ 's entire feature set copied rather than allowing Feature Copying to choose which features are copied. See

\footnotetext{
15 These Vocabulary Items are simplified in that I abstract away from whatever operation (e.g., Fission), separates the agreement features from the negative and imperative features. It would be empirically identical to suggest that there is no Fusion, but instead, mutual contextual allomorphy. We could propose that $\ddot{a} r$ is an expression of $\mathrm{C}_{[\mathrm{IMP}]}{ }^{0}$ in the context of $[\mathrm{NEG}]$, and $\mathrm{Pol}_{[\mathrm{NEG}]}{ }^{0}$ with $\phi$-features is realized as the imperative agreement paradigm in the context of $\left.\mathrm{C}_{[\mathrm{IMP}]}\right]^{0}$. I adopt the Fusion account here because it allows for a more straightforward account of the doubling of imperative and agreement features, as it joins them as a single node.
} 
also Kramer (2010) for a similar conclusion regarding Feature Copying in Amharic adjectival agreement. ${ }^{16}$

Because Feature Copying applies postsyntactically, it necessarily applies after Agree has taken place. This means that the $\phi$-feature values of the subject are known when Feature Copying applies, which opens the door for an understanding of the optionality in the case of [1PL] -me. Concretely, I propose that the operation of Feature Copying is optional when $\mathrm{C}^{0}$ is specified as [1PL]. This is similar to the analysis of Basque auxiliaries proposed by Arregi and Nevins (2012), where certain PF operations may apply (or not apply) based on $\phi$-feature specifications. The final formalization I adopt for Feature Copying Estonian Imperatives is presented in (27).

Feature Copying (Estonian Imperatives): Copy $\mathrm{C}^{0}$ 's features to an Agr node adjoined to $\mathrm{T}^{0}$ if $\mathrm{C}^{0}$ is specified for [IMP, NEG]. This is optional if $\mathrm{C}^{0}$ is specified as $[1 \mathrm{PL}]$.

A reviewer has two related questions about the arbitrariness of rules of Feature Copying. First, the reviewer observes that the optionality of first-person plural doubling is rather arbitrary as stated here. The issue of arbitrariness comes up again in Section 5, where some differences in patterns of doubling in other Finno-Ugric languages are investigated. There is some variation in what features are copied in languages with doubling, suggesting some degree of arbitrariness may be necessary.

Second, the reviewer asks whether the heads and features involved in Feature Copying rules like (27) are completely arbitrary. While I cannot offer a definitive answer to this question, I comment briefly on this question here. The question is both empirical and theoretical, and it has not yet been systematically investigated. However, the rule presented here shares similarities with other uses of Feature Copying in the literature (Kramer 2010; Norris 2014). First, Feature Copying copies features to an Agr node adjoined to some head postsyntactically. Second, the origin of the features is higher in the structure than the target; in other words, features are copied downward, as opposed to Agree, which can only transfer features upward, in at least some conceptualizations. ${ }^{17}$ Third, there is a sense in which Feature Copying takes place within a single domain reminiscent of Grimshaw's (1991/2005) Extended Projection: for Kramer (2010) and Norris (2014), features are copied from some nominal head to attributive adjectives, and for my analysis, features are copied from a verbal head to another verbal head. Whether these properties can hold for all plausible instances of Feature Copying is an issue that I must leave to future work.

Returning to the main point, when Feature Copying does not apply in these [1PL] contexts, the main verb is in a structural position that is identical (or very similar) to its position in negated indicative clauses: it is in $\mathrm{T}^{0}$ with no $\phi$-features. This is visible in the imperative structure in (28) and the indicative structure in (29).

\footnotetext{
16 Feature Copying of the kind proposed here is also similar to the operation of Enrichment proposed by Müller (2007), although Enrichment operates more locally, only allowing features to be duplicated inside a single complex head.

17 There are many existing proposals concerning the direction of Agree, including that it only transmits feature values downward and that it can transfer feature values in any direction. For recent discussion, see Bjorkman and Zeijlstra (2015) and Preminger and Polinsky (2015).
} 
(28)

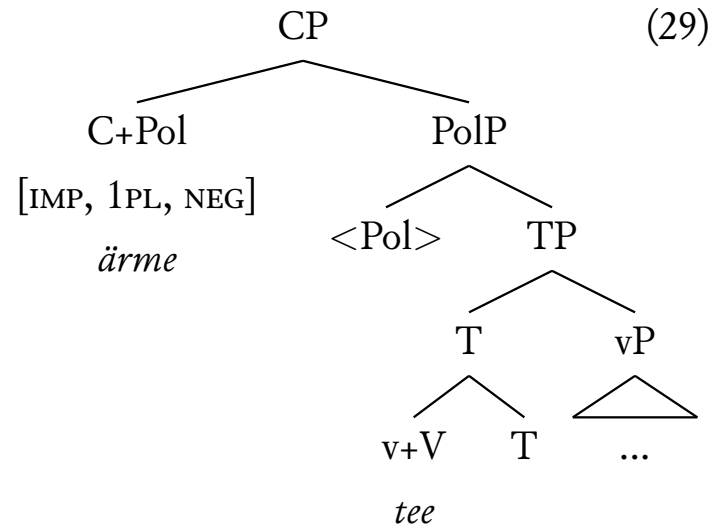

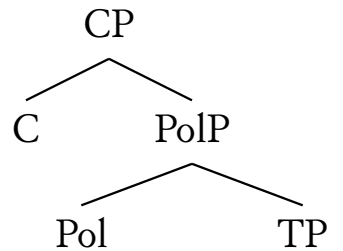

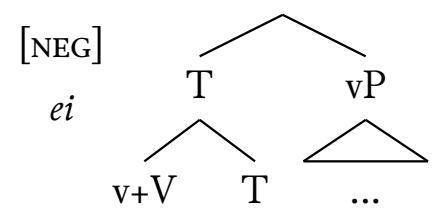

tee

In (28), $\mathrm{Pol}^{0}$ has raised to $\mathrm{C}^{0}$, but Feature Copying has not applied, leaving the main verb in $\mathrm{T}^{0}$ with no [IMP] feature nor $\phi$-features. This is the same as the main verb in a negated indicative clause: it has no $\phi$-features (nor the [IMP] feature, for that matter).

This analysis thus predicts that, when Feature Copying does not apply, the main verb should surface in its ordinary connegative form. It is actually somewhat difficult to tell, because for most verbs in the language, the connegative form is homophonous with the second-person singular imperative form. However, as noted in footnote 8 , there is one verb with distinct forms (minema 'go'), and it must be in the connegative form in first-person plural imperatives without doubling. This is shown in (30) and (31).

$$
\begin{aligned}
& \text { är-me lähe } \\
& \text { NEG.IMP-1PL go.CNG } \\
& \text { 'Let's not go' }
\end{aligned}
$$

$$
\begin{aligned}
& \text { *är-me mine } \\
& \text { NEG.IMP-1PL go.IMP.2sG } \\
& \text { Intended: 'Let's not go.' }
\end{aligned}
$$

The connegative form of minema 'go' is lähe, while its second-person singular imperative form is mine. Only lähe can be used in negated [1 PL] imperatives without Feature Copying, which is exactly what the Feature Copying analysis predicts.

Under this analysis, the relationship between the syntax of agreement (i.e., Agree) and its morphological expression is imperfect for negated imperatives: there is only one instance of Agree, but potentially two exponents of $\phi$-feature agreement. In fact, the analysis also requires an imperfect relationship for negated indicatives: one instance of Agree in the syntax, but no morphological expression. This is a complication, but it is warranted. Let us now discuss indicative clauses for some independent evidence for that claim.

\section{2 ei as a morphologically deficient negative auxiliary}

As we have seen, negated indicative clauses in Estonian do not show morphological agreement, regardless of tense.

(32) Sa ei vaata filmi.

2SG NEG watch movie.PAR

'You are not watching a/the movie.'

Sa ei vaada-nud filmi.

2SG NEG watch-PST.PCPL movie.PAR

'You did not watch a/the movie.' 
If we take the term negative auxiliary to mean that the negation word inflects like a verb, then Estonian ei does not qualify. It does not show verb-like inflection of any kind. If we take the canonical example of a negation particle to be a negation form that does not affect the form of the main verb (sYMMETRIC NEGATION in the terms of Miestamo 2005), Estonian ei does not seem to qualify with this either, as its presence prevents the main verb from showing agreement. Under the analysis I proposed above, Estonian $e i$ is the realization of $\operatorname{Pol}_{[\mathrm{NEG}]}{ }^{0}$, a head which bears $[u \phi]$ and establishes Agree in the syntax. In other words, it is syntactically a negative auxiliary. I believe that this is the right approach for the syntax of Estonian for two reasons.

First, discussion by Erelt (2003) and Tamm (2015) suggests that the negative auxiliary bore inflection in older forms of the language. Tamm provides the example in (34).

$$
\begin{aligned}
& \text { et } e-b \quad \text { se mei-lle woi mitte kuria teb-da. } \\
& \text { that NEG-3sG this we-ALL can.CNG NEG harm.PAR do-DA.INF } \\
& \text { 'That this cannot harm us.' }
\end{aligned}
$$

Here, the form of negation is $e b$, indicated as bearing third person singular agreement. Tamm also notes that, although ei does not show inflection in Standard Estonian, it does agree in some Southern varieties of the language. There is thus historical precedent and potential dialectal evidence for a negative auxiliary in Estonian.

Second, Estonian is the only language among its closest relatives where the negative auxiliary fails to inflect (Miestamo et al. 2015; Mitchell 2006). As we have seen, it inflects in Finnish, but it also inflects in the Finnic languages Ingrian, Karelian, Livonian, Veps, and Vod. ${ }^{18}$

$$
\begin{array}{ll}
\text { (35) } & \text { Ingrian (Mitchell 2006, 235) } \\
& e-n \quad \text { ompēle } \\
& \text { NEG-1sG sew } \\
& \text { 'I don't sew' } \\
\text { (36) } & \text { Karelian (Mitchell 2006, 235) } \\
& e-n \quad \text { šano } \\
& \text { NEG-1sG say } \\
& \text { 'I don't say' } \\
\text { (37) Livonian (Mitchell 2006, 230) } & \text { Miná ä- } b \\
& \text { 1sG NEG-1sG be-PRS.PCPL } \\
& \text { 'I am not.' } \\
& \text { Veps (Mitchell 2006, 230) } \\
& e-n \quad \text { to } \\
& \text { NEG-1sG bring } \\
& \text { 'I don't bring' }
\end{array}
$$$$
\text { (37) Livonian (Mitchell 2006, 230) }
$$

\footnotetext{
18 Some of the Finnic languages' names are rendered in English in a variety of ways. Veps is sometimes called Vepsian, and Vod is sometimes called Votic or Votian. Here, I have used the main entry name according to Ethnologue.
} 
(39) Vod (Mitchell 2006, 236)

$$
\begin{aligned}
& e-n \quad j \bar{o} \\
& \text { NEG-1sG drink } \\
& \text { 'I don't drink.' }
\end{aligned}
$$

In addition, though not shown here, all of the closely related Saami languages have inflecting auxiliaries (Toivonen and Nelson 2007, 8-9). ${ }^{19}$ Proposing that the Estonian $e i$ is still at some level a negative auxiliary thus puts it in line with the other members of its family and the closely related Saami languages.

Speaking more concretely, I propose that Estonian ei (or more accurately, the syntactic head $\mathrm{Pol}^{0}$ ) still has the syntax of a negative auxiliary. This means it is generated with $[u \phi]$ in the syntax, and it undergoes Agree with the subject, obtaining its $\phi$-features. Estonian has this in common with the languages where this agreement is overt. This is depicted in (40).

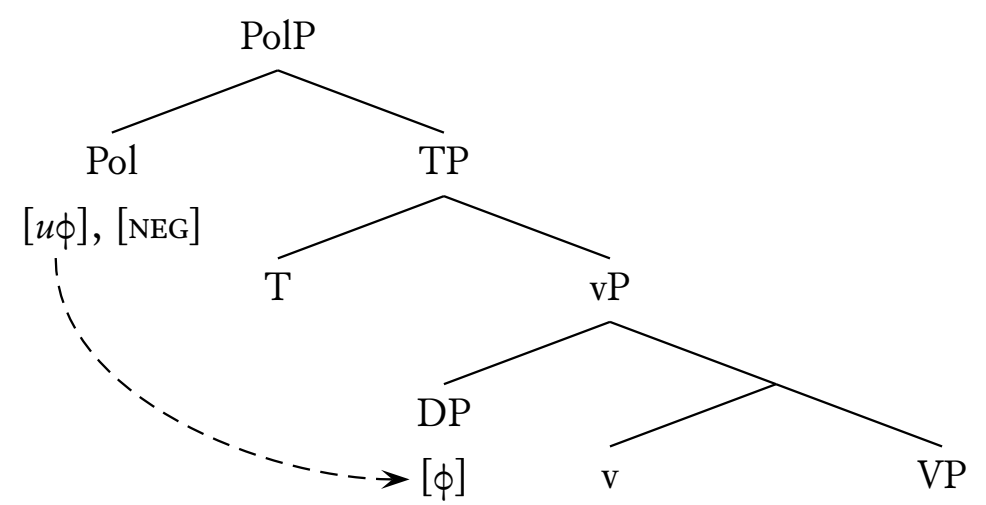

In (40), $\mathrm{Pol}^{0}$ establishes Agree with the subject DP in Spec,vP. Thus, $\mathrm{Pol}_{[\mathrm{NEG}]}{ }^{0}$ acquires a $\phi$-feature set in the narrow syntax, and this is the representation that undergoes Vocabulary Insertion in indicatives.

This is where Standard Estonian differs from the rest of the members of its family. Whereas a language like Finnish has multiple vocabulary items for $\operatorname{Pol}_{[\mathrm{NEG}]}{ }^{0}$, Estonian only has one: $e i$. Thus, when $\mathrm{Pol}_{[\mathrm{NEG}]}^{0}$ undergoes Vocabulary Insertion, $e i$ is inserted regardless of the $\phi$-features. An example terminal node is presented in (41), and the competitions for Finnish and Estonian are represented in (42) and (43), respectively.

(41) Example terminal node targeted for insertion:

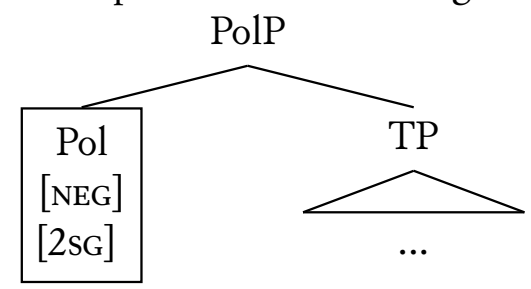

\footnotetext{
19 Toivonen and Nelson (2007) provide examples from South Saami and Inari Saami, but their discussion suggests this is the case in all of the Saami languages. The literature also contains examples from Finnmark Saami (Mitchell 2006), North Saami (Nickel 1990), Pite Saami (Wilbur 2014), and Skolt Saami (Feist 2010), all of which have agreeing negative auxiliaries.
} 
Finnish Vocabulary Items
a. Pol, [NEG, 1sG] $\leftrightarrow$ en
b. Pol, [NEG, 2sG] $\leftrightarrow e t \quad \Leftarrow$
c. Pol, [NEG, 1PL] $\leftrightarrow$ emme
d. Pol, [NeG, 2PL] $\leftrightarrow$ ette
e. Pol, [NEG, 3PL] $\leftrightarrow$ eivät
f. Pol, $[\mathrm{NEG}] \leftrightarrow e i$

Estonian Vocabulary Items

a. Pol, $[\mathrm{NEG}] \leftrightarrow e i \quad \Leftarrow$

Thus, the Estonian ei amounts to a highly underspecified vocabulary item for negation. Following standard DM assumptions, the vocabulary item matching the largest subset of features of the terminal node is inserted (on the Subset Principle, see Halle 1997; Hankamer and Mikkelsen 2005, a.o.). For Finnish, this is et, which matches the entire set. For Estonian, ei matches a subset of the features of the terminal node, and there are no Vocabulary Items matching a greater set. Regardless of the $\phi$-feature set, ei is inserted. Thus, the indicative negative auxiliary in Estonian establishes a syntactic Agree relationship, but that relationship is not realized by morphological agreement.

As an alternative, it could be proposed that the difference between Estonian and other Finno-Ugric languages is that $\mathrm{Pol}_{[\mathrm{NEG}]}^{0}$ in Estonian has lost its status as a $\phi$-feature probe. There would be thus no agreement in the syntax, and the spell-out would be the same. This provides a more transparent mapping between the syntax and morphology of Estonian $e i$, but it also sets Estonian apart from the rest of its relatives in terms of the syntax. I believe this alternative analysis and the analysis I propose are indistinguishable in terms of empirical coverage for indicatives. Conceptually, my analysis is preferable for two reasons. First, it fits within a general theory of language variation where variation is located in the morphology of languages rather than their syntax (Chung 2013, 2014). ${ }^{20}$

Second, the analysis whereby Estonian ei establishes Agree in the syntax despite its lack of demonstrable agreement is easier to incorporate with an analysis of the pattern of negated imperatives. In that analysis, the imperative negative auxiliary ära is the spell-out of a complex head involving [NEG], [IMP], and $[\phi]$. If $\mathrm{Pol}_{[\mathrm{NEG}]} 0$ is simply not a $\phi$-feature probe (i.e., if it lacks $[u \phi]$ ), then the only way for $\mathrm{C}_{[\mathrm{IMP}]}{ }^{0}$ to have $\phi$-features in its feature bundle would be if $\mathrm{C}_{[\mathrm{IMP}]}^{0}$ could idiosyncratically select $\mathrm{Pol}_{[\mathrm{NEG}]}^{0}$ with $\phi-$ features, which seems difficult to motivate independently. It is also not obviously superior to propose that $\mathrm{C}_{[\mathrm{IMP}]}$ Agrees directly with the subject, as this would mean there are two $\phi$-feature probes in affirmative imperatives $-\mathrm{C}_{[\mathrm{IMP}]}^{0}$ and $\mathrm{Pol}^{0}$, necessary for affirmative indicatives-even though there is only one instance of agreement. It also leads to a system that is less uniform, as the analysis I propose holds that there is always only one $\phi$-feature probe per finite CP, and it is located on $\mathrm{Pol}^{0}$. For these reasons, I do not adopt an analysis where $\mathrm{Pol}_{[\mathrm{NEG}]}{ }^{0}$ lacks $[u \phi]$ in Estonian.

\footnotetext{
20 It is also worth noting here that the account whereby $\mathrm{Pol}_{[\mathrm{NEG}]}{ }^{0}$ is simply not a probe in Estonian is incompatible with the proposal that some clausal features are born on $\mathrm{C}^{0}$ but inherited by the head of $\mathrm{C}^{0}$ 's complement (see Brattico et al. 2014 for a discussion of this in the context of Finnish). Under this analysis, it is $\mathrm{C}^{0}$ that determines the features relevant for the clause. Thus, whether $\mathrm{C}^{0}$ 's complement is $\mathrm{Pol}_{[\mathrm{NEG}]}^{0}$ or simply $\mathrm{Pol}^{0}$ would be irrelevant, formally speaking.
} 


\subsection{Negated Imperatives: analysis summary}

In this section, I presented an analysis of the agreement patterns in negated imperatives in Estonian as resulting from syntactic and morphological agreement. On the syntactic side, I proposed that $\mathrm{Pol}_{[\mathrm{NEG}]}{ }^{0}$ Agrees with the subject before moving to $\mathrm{C}_{[\mathrm{IMP}]}{ }^{0}$, ultimately spelling out as the imperative negative auxiliary ära. In the morphology, the combination of [IMP] and [NEG] triggers Feature Copying from $\mathrm{C}^{0}$ to the verbal complex in $\mathrm{T}^{0}$. In Estonian, Feature Copying is obligatory for all combinations of person and number except first-person plural, where agreement is only obligatory on the negative auxiliary. As a consequence of this proposal, I also discussed the indicative negative auxiliary ei, proposing that it establishes Agree in the syntax even though that agreement is not reflected morphologically as it is in all of Estonian's closest relatives.

The upshot of the analysis is that the complicated morphology of agreement exponence in Estonian disguises a system that is straightforward syntactically. There is one head that bears $[u \phi]-\mathrm{Pol}^{0}$ - and that head always establishes Agree in the syntax. This opens the door for the possibility of a more uniform analysis of the syntax of agreement in the Finnic and Saamic languages. This line of research ties language-specific stipulations about Estonian (e.g., doubling, ei showing no inflection) to the morphology as opposed to the syntax, following the argumentation of Chung (2014).

This analysis also involves a maximally transparent syntax for negated imperatives in Estonian, as the syntax of imperativity is simply laid on top of the syntax of negation. While I believe this is a welcome result, it is not necessarily an argument in favor of the current proposal, as it is well-known that negation and imperativity are not readily combined in the world's languages. In the WALS chapter on the prohibitive (van der Auwera et al. 2013), only $22.8 \%$ of languages in the sample form negative imperatives with a morphologicallyimperative verb and the same negation as declaratives, and we would expect that number to be higher if there were no issues combining imperative and negation. Furthermore, based on surface forms alone, Estonian does not fall into that group. Rather, Estonian is a member of the largest group of languages in the sample (36.7\%), whose negative imperatives utilize a special form of negation. It is thus reasonable to question whether it is right to ascribe the transparent syntax I have proposed for negated imperatives in the language.

In the next section, I consider the prospects for an account of Estonian that takes a different tack, treating negation and imperativity as syntactically incompatible. The alternative hypothesis I will consider also differs from the analysis presented in this section in that it accounts for doubling in imperatives by adding a second $\phi$-feature probe to the clause. As I have mentioned, this is in line with some previous work on multiple agreement for $\phi$-features (Baker and Willie 2010; Carstens 2001; Henderson 2006; Polinsky 2016). I show that the account struggles to account for the optionality of agreement in first-person plural imperatives. I also discuss some conceptual reasons why the alternative developed in the next section is inferior to the analysis I argued for in this section. 


\section{$4 \quad$ Alternative: Multiple $\phi$-feature probes}

The morphological analysis presented in Section 3 requires a morphological method of feature transfer (Feature Copying), and thus it is worth considering the prospects for an account that does not utilize additional mechanisms. There are no previous accounts that can be compared, so far as I know. Instead, I present the best account I have been able to construct, building on the idea that imperative syntax and ordinary negation syntax are incompatible (Laka 1990; Zanuttini 1994). This alternative analysis accounts for doubling through the use of multiple $\phi$-feature probes, as has been proposed for other instances of multiple $\phi$-feature exponence in Archi (Polinsky 2016), Ibibio (Baker and Willie 2010), and Swahili (Carstens 2001; Henderson 2006). We will see that it cannot straightforwardly account for the optionality of doubling in [1PL] contexts. Furthermore, it does not generalize as easily to the morphological patterns seen in other Uralic languages, which is the focus of Section 5.

\subsection{Laka (1990): Negation and imperative realize the same head}

To account for the fact that negation and imperativity are incompatible in some languages, Laka (1990) proposes that negation and imperative realize the same head. Laka calls this head $\Sigma^{0}$, and $\Sigma^{0}$ selects a TP complement. Thus, a clause can either have $\Sigma^{0}$ with an imperative feature [IMP] or $\Sigma^{0}$ with a negation feature [NEG], but not both at once. This is shown in (44) and (45).

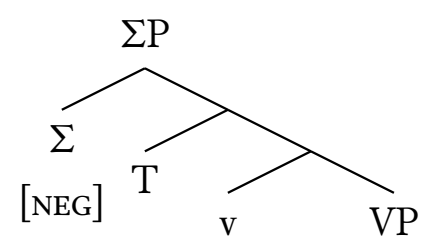

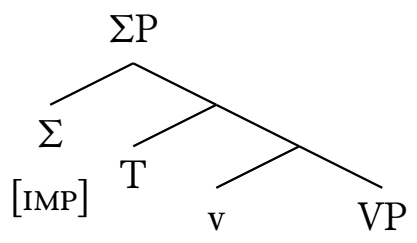

Laka's discussion about imperativity focused on Spanish, where the morphological imperative form cannot be combined with the standard negation marker. Instead, the language uses a subjunctive verbal form. To adapt this for Estonian, we would further propose that it is $\Sigma^{0}$ that bears unvalued $\phi$-features in imperative clauses in Estonian. I leave open the question of whether all $\Sigma^{0}$ heads bear $[u \phi]$ (that is, both $\Sigma^{0}$ with [NEG] and $\Sigma^{0}$ with [IMP]) or if it is just the imperative $\Sigma^{0}$. This differs from the analysis proposed in Section 3, as imperative and negation are realized by separate heads in that analysis $-\mathrm{C}^{0}$ and $\mathrm{Pol}^{0}$, respectively-and are thus fully compatible.

Since negation and imperative features would be syntactically incompatible under this analysis, Estonian would require an alternative structure to express prohibitive semantics. Namely, Estonian makes use of ära, a word traditionally called the imperative negative auxiliary. To concretize this traditional definition, I suggest that $\ddot{a} r a$ is a $\mathrm{C}^{0}$ that selects a $\Sigma$ P with [IMP] features. This constrains ära such that it would only surface in imperative clauses. Because ära shows agreement, it must be idiosyncratically associated with its own set of unvalued $\phi$-features $[u \phi]$. Let us see how this alternative hypothesis works by walking through a sample derivation.

In the first step, $\Sigma^{0}$ (with imperative features) establishes Agree with the subject DP as normal, schematized by the dashed arrow in (46). 
(46)

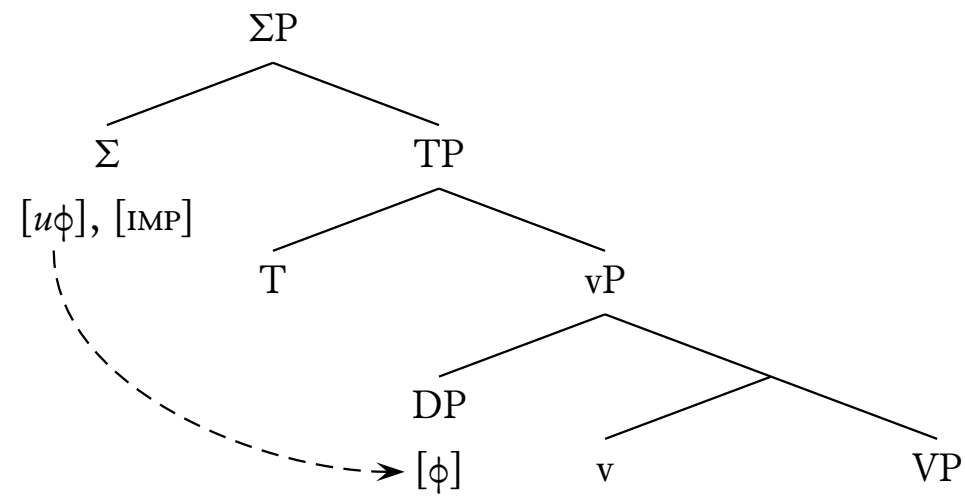

Then, assuming that the verb moves up the clausal spine to $\Sigma_{[\mathrm{IMP}]}^{0}$-just as I proposed in Section 3-the imperative verb comes to reflect the $\phi$-features of the imperative subject. Under this account, this much would be identical for both affirmative and negated imperatives.

In the second step, ära (more accurately, the $\mathrm{C}^{0}$ that ultimately spells out as $\ddot{a} r a$ ) is merged with the structure, and it too has unvalued $\phi$-features. It searches its c-command domain for a suitable set of $\phi$-features, which I assume it finds on the subject-which has moved to Spec, $\Sigma \mathrm{P}$ - for concreteness. ${ }^{21}$

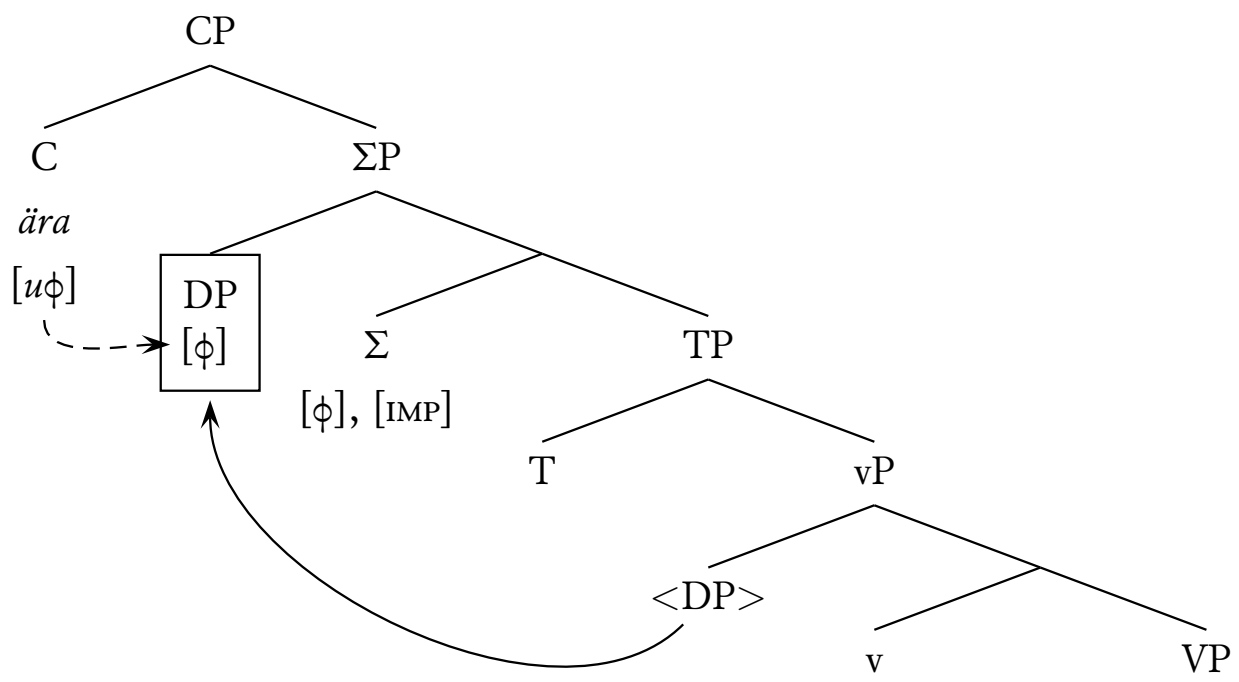

We thus have two instances of $\phi$-features in the same clause: on $\mathrm{C}^{0}(\ddot{a} r a)$ and $\Sigma^{0}$ (main verb). ${ }^{22}$

This analysis succeeds in certain respects. First, it captures the fact that ära is restricted to imperatives, as ära selects only $\Sigma \mathrm{P}$ headed by $\Sigma_{[\mathrm{IMP}]}^{0}$. Second, it captures the fact that $\ddot{a} r a$ and the main verb must bear the same set of $\phi$-features, as they acquire their $\phi$ features from the same source. However, what is not immediately clear from this analysis is why ära's $\phi$-feature marking is from the imperative paradigm rather than the indicative paradigm (or some other paradigm entirely). It cannot be because ära is string-adjacent

\footnotetext{
21 The particulars of this analysis would not change if the goal was $\Sigma^{0}$ or $\Sigma$, as in the analyses of Baker and Willie (2010) and Henderson (2006).

22 At this point, this alternative analysis is quite similar to the analyses of multiple $\phi$-feature agreement in some Niger-Congo languages: see Carstens (2001) and Henderson (2006) for discussion of Swahili (Bantu) and Baker and Willie (2010) for Ibibio (non-Bantu).
} 
to $\Sigma_{\text {[IMP] }}^{0}$ (e.g., as a kind of contextual allomorphy) because $\ddot{a r a}$ and the main verb can be separated, as in (48) and (49).

Ja är-ge te oue-s kukku-ge, libe on.

and NEG.IMP-2PL you.PL outside-INE fall-IMP.2PL slippery be.3.PRS

'And don't you fall down outside. It's slippery.'

(BALANCED)

Är-ge te seda arva-ke ega loot-ke.

NEG.IMP-2PL you.PL that.PAR think-IMP.2PL or hope-IMP.2PL

'Don't you think or hope that.'

(BALANCED)

In these examples ärge is separated from the main verb(s), suggesting that an analysis based on linear adjacency would run into trouble with a broader range of data.

A more promising possibility for ära's imperative marking is that ära is associated not only with $[u \phi]$, but with its own imperative feature [IMP]. With this additional stipulation, there would be two components that are used to account for the imperative characteristics of ära under this analysis. It would be restricted to imperative clauses because it only selects $\Sigma \mathrm{P}$ with imperative features. Its inflection would be from the imperative set because it is associated with its own imperative feature.

In this respect, the analysis proposed in Section 3 is superior, as the imperative aspects of $\ddot{a} r a$ are tied to the same claim. In that analysis, $\ddot{r} r a$ is the spell-out of a complex head containing $\mathrm{Pol}_{[\mathrm{NEG}]}{ }^{0}$ (with $\phi$-features) and $\mathrm{C}_{[\mathrm{IMP}]}{ }^{0}$. Because this $\mathrm{C}_{[\mathrm{IMP}]}^{0}$ is the source of imperative-marking under this analysis, we capture the fact that $\ddot{r} a$ only surfaces in imperative clauses. It is that same feature that is responsible for the fact that the $\phi$-feature inflection is from the imperative paradigm. Thus, though ära's restriction to imperatives must be stipulated in either account, the alternative account currently under discussion would require two separate stipulations to capture all of ära's imperative properties, but the account proposed in Section 3 requires only one.

However, a bigger concern for the account currently under consideration is that there is no clear path to generate the optionality of [1PL] doubling. Recall that [1PL] can be dropped on the main verb, but importantly, this is only true in negated imperatives. In affirmative imperatives, the verb must bear agreement, even in the case of [1 PL] agreement. Leaving off [1 $\mathrm{PL}]$ agreement in affirmative imperatives is ungrammatical, as shown in (50).

$$
\begin{aligned}
& \text { * }(\mathrm{Me}) \text { lähe sinna! } \\
& \text { we go.CNG there } \\
& \text { Intended: 'Let's go there!' }
\end{aligned}
$$

Under this account, both the main verb and ära establish Agree relationships and acquire $\phi$-features, and there is no formal link between ära's agreement and the main verb's (i.e., $\Sigma^{0}$ 's) agreement. The main verb has to be able to see that ära is present, and when it is, the verb can drop its [1PL] inflection, informally speaking.

This hypothetical operation is reminiscent of the Distributed Morphology operation Impoverishment, so it is worth taking a moment to consider such an approach. As we will see, the operation required would be significantly more powerful than existing formalisms for Impoverishment. 


\subsection{Optional first-person plural agreement is not Impoverishment}

Broadly speaking, Impoverishment removes features that were present in the syntactic representation before Vocabulary Insertion can take place. Informally, Impoverishment in this case would remove [1PL] features from $\Sigma^{0}{ }_{\text {[MP] }}$ just in case it is in a structure with a $\mathrm{C}^{0}$ with [IMP], i.e., $\ddot{a r a} .^{23}$ This way of looking at [1PL] optionality is essentially the reverse of how I framed it in Section 3. Here, agreement doubling always happens, but agreement on the main verb can be Impoverished if it is [1 PL]. In the analysis I proposed, doubling is the norm, but the doubling operation can be ignored or might not apply in the context of [1PL].

At first glance, the Feature Copying operation that I propose seems just as arbitrary as the Impoverishment operation described here. Unlike Feature Copying, Impoverishment has received a fair amount of attention in the literature, largely focused on how exactly it should be constrained. Based on the existing literature on Impoverishment, it seems to me that the Impoverishment-like operation that this alternative account requires would be outside the bounds of our current understanding of Impoverishment.

It has been proposed that rules of Impoverishment are not arbitrary, but emerge from cross-linguistically supported scales of markedness (see, e.g., Arregi and Nevins 2012; Keine and Müller 2014). It is not clear how [1PL] could be considered more marked than other sets of $\phi$-features, even in the context of imperatives. For example, in the system developed by Harley and Ritter (2002), first-person plural must be less-marked than second-person plural: it contains the default [SPEAKER] feature whereas second-person plural comes pre-specified with the feature [ADDRESSEE $].{ }^{24}$ Unlike the first-person plural, second-person plural must always be marked on the main verb in a negated imperative (see (18b)). Thus, it seems unlikely that the optionality of [1PL] agreement on the main verb in Estonian negated imperatives has anything to do with cross-linguistic markedness.

It has also been proposed that Impoverishment rules refer only to isolated feature bundles, not to the contexts in which those feature bundles appear (see, e.g., Keine 2010; Müller 2007). Thus, for example, a gender feature might be deleted just in case it is in a feature bundle with [PL], capturing the fact that gender features are neutralized in the plural for some languages (Corbett 1991; Kramer 2015). Along these lines, one might suggest that $[1 \mathrm{PL}]$ is deleted in Estonian in the context of [IMP]. However, this would be too strong: in affirmative imperatives, where [1PL] and [IMP] can readily appear in the same feature bundle, agreement is obligatory, as we just saw in (50). The [1PL]-me can only be deleted when the higher $\mathrm{C}^{0}$ that ultimately spells out as ära is present- in other words, it is not triggered by the mere presence of [1PL] and [IMP] in the same feature bundle.

Finally, Arregi and Nevins (2012) propose that Impoverishment rules may refer to more than one feature bundle, but those bundles must be at least in the same M-word (roughly, the same complex head). In order for this to be applicable in Estonian, ära and the main verb would have to be one M-word. However, this seems unlikely, as ära and the

\footnotetext{
23 Recall that, under this alternative analysis, ära is not associated with the morphosyntactic feature [NEG].

24 The feature [SPEAKER] is not always a default. Harley and Ritter (2002) propose that [SPEAKER] is always fully specified in languages with an inclusive/exclusive distinction for first-person plural. Estonian does not have this distinction, and so [SPEAKER] must be supplied as a default in Estonian. As a result, it does not count for Harley and Ritter's node-counting metric for markedness.
} 
main verb can be separated, as seen in (48)-(49). Additional examples are shown in (51) and (52).

$$
\begin{aligned}
& \text { Ära bomme tule! } \\
& \text { IMP.NEG tomorrow come.IMP.2sG } \\
& \text { 'Don't come tomorrow!' } \\
& \ddot{A} \text {-me selle-st robkem räägi! } \\
& \text { IMP.NEG-1PL this-ELA more speak } \\
& \text { 'Let's not speak about this anymore!' }
\end{aligned}
$$

In (51), ära is separated from the main verb tule 'come' by bomme 'tomorrow', and in (52), they are separated by two words. Significantly, (52) involves a main verb with no agreement exponence, which is exactly the environment where the putative rule of Impoverishment would have to apply.

Thus, it seems unlikely that the optionality of [1PL] agreement on the main verb in negated imperatives is to be explained by Impoverishment. It would involve deletion of features that are not driven by markedness in any straightforward way, and it would require a greater amount of syntactic context than has previously been included in the domain of Impoverishment. ${ }^{25}$

\subsection{Alternative: prospects \& summary}

The syntactic account presented in this section eschews DM postsyntactic operations in favor of syntactic Agree relations. This fits with a general theory of clausal agreement wherein more than one head in a clause can serve as a $\phi$-feature probe (Baker and Willie 2010; Carstens 2001; Henderson 2006; Kalin and van Urk 2015; Polinsky 2016). An even stronger version of this theory is one in which Agree underlies all forms of morphological agreement, and all instances of syntactic Agree result in morphological agreement. ${ }^{26}$ This would, of course, provide a transparent mapping between the syntax and morphology, at least as far as agreement is concerned, and this would be a positive result.

However, the analysis struggles to account for the full range of patterns in negated imperatives. Because the groundwork for extended exponence is laid at the start of the derivation, it is difficult to produce the examples where [1PL] agreement is not doubled. There is no formal connection made between the $\phi$-feature probe of ära and the $\phi$-feature probe of the main verb. I conclude that the account that makes use of morphological operations is the more promising approach of the two. At a minimum, it is able to produce the attested forms: first-person plural agreement on the main verb is optional only in the context of $\ddot{a} r a$ because $(\mathrm{i})$ it is $\mathrm{C}_{[\mathrm{IMP}]}{ }^{0}$ (ära) that passes the features to the main verb,

\footnotetext{
25 To be sure, the Impoverishment approach is not inconceivable. It may be that future research on Impoverishment finds reason for it to be less constrained than its current form. In that case, it would be worth revisiting the alternative analysis presented here to see if it can be subsumed under the umbrella of Impoverishment. I thank an anonymous reviewer for helpful discussion of this point.

26 Polinsky (2016) does not adopt the strong version of Agree, wherein Agree underlies all forms of morphological agreement. In particular, she argues that nominal concord in Archi, which is unquestionably a form of morphological agreement, does not arise from Agree. Instead, she advocates for the view that concord is a fundamentally different operation from argument-predicate agreement (see also den Dikken 2006; Kramer 2009; Norris 2014).
} 
and (ii) the operation is postsyntactic, meaning it can be value-sensitive. Furthermore, my analysis locates plausibly general facts about (Uralic) imperatives in the syntax, and it locates Estonian-specific facts in the morphology, which I take to be a desirable result (see also Chung 2013, 2014).

The alternative account also does not fare as well in another domain: the patterns of agreement and imperative-marking in other Uralic languages. In this alternative account, both instances of imperative-marking and agreement are syntactically real- that is, they are both connected to features in the syntax. However, there are a number of Uralic languages where the main verb bears no imperative marking nor inflection in negated imperatives, suggesting the imperative-marking on the negative auxiliary is in some sense more robust than that on the main verb. From the perspective of the analysis I argue for, that is because it is only the imperative-marking on the negative auxiliary that is connected to the syntactic imperative feature. Let us now turn to a discussion of the patterns in other languages.

\section{$5 \quad$ Negative Imperatives across Uralic}

The analysis I argue for contains both Estonian-specific and more general proposals. On the general side, the analysis holds that the syntactic locus of imperativity is $C^{0}$. Thus, in a language like Estonian, where imperativity is expressed twice in negated imperatives, it is the imperativity on the negative auxiliary that corresponds to real (that is, syntactic) imperative features. From the perspective of this analysis, the doubled imperative marking on the verb is special. Also on the general side, the analysis holds that heads other than $\mathrm{T}^{0}$ may be the main $\phi$-feature probe in a language, though this much is already assumed in much research on Finnish (Holmberg and Nikanne 2002; Holmberg et al. 1993; Mitchell 1991).

On the Estonian-specific side, the syntax of Estonian involves head movement of $\mathrm{Pol}_{[\mathrm{NEG}]}{ }^{0}$ to $\mathrm{C}_{[\mathrm{IMP}]}^{0}$ followed by Fusion, which results in a negative auxiliary that is particular to imperative clauses. This much is shared by some (not all) Uralic languages. Further, Estonian has a language-particular rule of Feature Copying, which copies features from $\mathrm{C}^{0}$ to $\mathrm{T}^{0}$. Again, some (not all) Uralic languages share this property.

In this section, I discuss the picture from other languages within the Uralic family, focusing on languages that have negative auxiliaries at least some of the time. I show that peeling away some of the Estonian-specific operations predicts the existence of other patterns that are attested in other Uralic languages. I also show that, in virtue of the general proposal that imperativity is high, there is a pattern of imperativity and $\phi$-feature marking that is predicted to be nonexistent. Based on the sample in Miestamo et al. (2015), this prediction is borne out for Uralic. Thus, the analysis presented here receives additional support from other Uralic languages.

\subsection{Languages (almost) like Estonian}

Vod, Livonian, Skolt Saami, and Finnish exhibit very similar morphology in their negated imperative clauses. They have a special negative auxiliary just for negated imperatives. In 
addition, the main verb reflects imperativity in negated imperatives, and in Livonian and Vod, the main verb also reflects agreement.

(53) Livonian: doubled imperative + agreement (Metslang et al. 2015, 440)
a. alā and-o
IMP.NEG.2SG give-IMP.2sG
'Don't give'
b. al-gid anda-gid
NEG.IMP-2PL give-IMP.2PL
'Don't give'

(54) Vod: doubled imperative + agreement (Rozhanskiy and Markus 2015, 494)
a. elä näe
IMP.NEG.2sG See.IMP.2SG
'Don't see!'
b. elka näbka
IMP.NEG.2PL see.IMP.2PL
'Don't see!'

(55) Finnish: doubled imperative (+ 2sG agreement) (Sulkala and Karjalainen 1992)
a. älä tule
IMP.NEG.2sG come.IMP.2sG
'don't come'
b. äl-kää tul-ko
NEG.IMP-2PL come-IMP.CNG
'don't come'

(56) Skolt Saami: doubled imperative only (Miestamo and Koponen 2015, 360)
a. jeällled porru/poor
IMP.NEG.2PL eat.IMP.CNG/CNG
'Don't eat!'
b. jeällap porru
IMP.NEG.1PL eat.IMP.CNG
'Let's not eat!'

In terms of the analysis proposed here, these languages would all have rules of Feature Copying, but they would have to be slightly different from Estonian's. Doubling in Vod and Livonian is always obligatory. In Skolt Saami, Feature Copying copies only the imperative feature, but that copying is optional for $[2 \mathrm{PL}] .{ }^{27}$ When the imperative feature is not copied, then the main verb surfaces in its ordinary connegative form, just as in [1PL] contexts for Estonian. In Finnish, in most cases, the main verb only reflects imperativity (with the suffix -ko) and not $\phi$-features- the one exception is second-person singular. Thus, it is like Skolt Saami in that most scenarios involve copying only the imperative feature, but slightly different in that it requires copying $\phi$-features in second-person singular. These patterns suggest a degree of arbitrariness among the languages with doubling of some

\footnotetext{
27 Alternatively, in line with the analysis of Estonian $e i$, we could propose that all the features are copied, but the $\phi$-features do not affect vocabulary insertion in Skolt Saami.
} 
kind, reminiscent of the kinds of seemingly arbitrary restrictions on PF operations for the varying dialects of Basque uncovered by Arregi and Nevins (2012).

\subsection{Languages with no Feature Copying}

There are also multiple Uralic languages which reflect imperativity only on the negative auxiliary and not on the main verb. Instead, the main verb in a negated imperative is indistinguishable from the form of a verb in a negated indicative clause. This is observable in Erzya, Forest Enets, Mari, North Saami, Pite Saami, South Saami, and Tundra Nenets. I present only the imperative examples.

Erzya (Hamari and Aasmäe 2015, 299)
a. il'a učo!
NEG.IMP.2SG wait.CNG
'do not wait!'
b. il'a-do učo! NEG.IMP-2PL wait.CNG 'do not wait!'

(58) Forest Enets ${ }^{28}$ (Siegl 2015, 50)

ið d'ori-r

NEG.IMP.2sG speak-FRQ.CNG

'don't speak'

(59) Eastern Mari (Saarinen 2015, 335)
a. $i-t \quad t o l$ IMP.NEG-2SG come.CNG 'don't come'
b. i-da tol IMP.NEG-2PL come.CNG 'don't come'

(60) North Saami (Nickel 1990, 61)
a. ale boaðe
IMP.NEG.2SG come.CNG 'don't come'
b. allet boaðe
IMP.NEG.2PL come.CNG 'don't come'

\footnotetext{
28 The imperative system of Forest Enets is complex, but Siegl (2015) explains it very carefully. The only person and number combination that has a distinct form of imperative negation is second-person singular. Other persons and numbers use the same negative auxiliary as indicatives and thus, negated imperatives and negated indicatives are formally indistinct for those persons and numbers.
} 
(61) Pite Saami (Wilbur 2014, 160, 181) ${ }^{29}$
a. ele tsábme!
NEG.IMP.2sG hit.CNG
'Don't hit!' (said to a child)
b. ellet/illut
NEG.IMP.2PL
(no translation)

(62) South Saami ${ }^{30}$ (Blokland and Inaba 2015, 382)
a. aellieb båetieb
IMP.NEG.2SG come.CNG
'don't come'
b. aellebe baietieb
IMP.NEG.2PL come.CNG
'don't come'

(63) Tundra Nenets (Eastern Dialect, Taymyr Subdialect) (Mus 2015, 80-81)
a. śimi ńo-n xaada-?!
1sG.ACC NEG.IMP-2sG kill-CNG
'Do not kill me!'
b. tańa ńo-xo-ńi? xań-?!
there NEG.IMP-HORT-2DU go-CNG
'Do not go there!'

In terms of my analysis, these languages all involve creation of a complex head comprising $\mathrm{Pol}^{0}$ and $\mathrm{C}^{0}$. This creates the negative auxiliary that is particular to imperative clauses. However, unlike Estonian, these languages do not have an additional rule of Feature Copying. Instead, the verb surfaces in its ordinary connegative form.

These languages also provide an argument in favor of the high origin of imperative features. In Section 2.1, I noted that Nelson (1998) proposed that imperative features in Finnish were generated lower (in $\mathrm{T}^{0}$ ). This was her analysis for the Finnish morpheme $-k_{0}$ that appears on the main verb in all negated imperatives except second-person singular. Nelson does state that there is a special negative auxiliary for imperatives (p. 171), but she does not specify how these morphological forms are generated. However, given that imperativity is otherwise lower in her analysis, it seems that the special negative imperative auxiliary is the unexpected part of the construction, with the main verb bearing the syntactic imperative feature. The languages of this class suggest that that is not right- it is the negative auxiliary that bears the main marker of imperativity, and imperative marking is copied onto the main verb in some languages.

\footnotetext{
29 Wilbur provides only one complete example of a negated imperative. However, he does provide forms for the imperative negative auxiliary, and discussion surrounding negation (pp. 159-60) suggests that the main verb is identical in indicative and imperative negation, which means that it does not inflect for imperative features.

30 South Saami has two negated imperative auxiliaries. One is used for prohibitives (the forms presented here), and one is used for warnings. Blokland and Inaba (2015) call the latter forms APPREHENSIVEs, and they behave identically to prohibitives as far as the data given here are concerned.
} 


\subsection{A gap: No imperative marking on the negative auxiliary}

The observations seen so far are summarized in Table 3 below.

\begin{tabular}{ccc}
\hline Negation & Main verb & Languages \\
\hline$[$ IMP $],[\phi]$ & {$[$ IMP $],[\phi]$} & Votic, Estonian, Livonian \\
{$[$ IMP $],[\phi]$} & {$[$ IMP $]$} & Finnish, Skolt Saami \\
{$[$ IMP $],[\phi]$} & $\emptyset$ & Erzya, Forest Enets, Eastern Mari, \\
& & North Saami, Pite Saami, South Saami \\
\hline$[\phi]$ & {$[$ IMP $],[\phi]$} & Unattested \\
{$[\phi]$} & {$[$ IMP $]$} & Unattested \\
\hline
\end{tabular}

Table 3: Imperative and $\phi$-feature marking in Uralic imperative clauses

The table focuses on just those Uralic languages where negation bears agreement in imperative clauses. The top three rows show the languages just discussed, where negation inflects for imperative features and $\phi$-features. The bottom two rows present two kinds of languages that are unattested in Miestamo et al. 2015. In these patterns, imperative features are reflected only on the main verb, not on the negative auxiliary. A toy example based on Finnish is presented in (65), with the indicative in (64) for reference.

$$
\begin{aligned}
& \text { e-tte tule } \\
& \text { NEG-2PL come } \\
& \text { 'You (PL) do not come.' } \\
& \text { e-tte tul-ko } \\
& \text { NEG-2PL come-IMP } \\
& \text { 'Don't come.' (Hypothetical Finnish) }
\end{aligned}
$$

In standard Finnish, the main verb does reflect imperativity in negated imperatives, but so does negation: it is älkä̈ rather than the indicative ette as in the hypothetical Finnish example in (65).

This gap within the typology of Uralic negation (so far as I know) is predicted by my analysis, and it connects back to the question of which imperative markers correspond to imperative features in the syntax. In my analysis, the source of imperative-marking on the negative auxiliary is the syntactic head bearing imperative features, i.e., $\mathrm{C}^{0}$, located high in the clausal structure. The negative auxiliary comes to reflect imperative features because it undergoes head movement to $\mathrm{C}^{0}$. Thus, the imperative marking on the negative auxiliary is connected to the syntactic location of imperative in the clause.

In contrast, the imperative-marking on the main verb is not connected directly to the syntactic locus of imperativity. Rather, it is connected indirectly via the imperative features of the negative auxiliary. Because the negative auxiliary (i.e., negation) intervenes between the imperative $\mathrm{C}^{0}$ and the main verb, there is no way for the verb to raise to $\mathrm{C}^{0}$ without passing the negative auxiliary. Instead, it is the negative auxiliary that is associated with imperativity in the syntax, and these imperative features are sometimes passed to the main verb. This is essentially the same explanation for the languages whose indicative 
connegative and imperative connegative forms are identical: the imperative marking on the negative auxiliary is syntactically real, and the marking on the main verb (when present) is redundant morphology.

At this point, I would like to note that the alternative analysis presented in Section 4 does not straightforwardly predict this same gap. Recall that, under that analysis, the negated imperative is formed from by merging the imperative negative auxiliary $\left(\mathrm{C}^{0} /\right.$ ära $)$ with an affirmative imperative clause $\left(\Sigma \mathrm{P}\right.$ headed by $\left.\Sigma_{\text {[тм] }}^{0}\right)$. The imperative features and $\phi$-feature probes associated with $\mathrm{C}^{0}$ and $\Sigma^{0}$ are independent of each other; just as it is possible for both to be associated with [IMP] and $[u \phi]$, it should be possible for one to be associated with [IMP] and the other with $[u \phi]$, all else being equal. Thus, $\Sigma^{0}$ could be associated with [IMP], and $\mathrm{C}^{0}$ could be associated with $[u \phi]$, and the result would be very similar to the proposed gap: a negation word with non-imperative agreement, and a main verb with imperative-marking but no agreement. ${ }^{31}$

\section{Conclusion}

In this paper, I have argued for a straightforward syntax for agreement in Estonian negated clauses. $\mathrm{Pol}_{[\mathrm{NEG}]} 0$ is always the only $\phi$-feature probe, even when morphological agreement is realized twice or not at all. The upshot of this claim is that the syntax of agreement in Estonian need not be radically different from its neighbors. The analysis presented here is also an argument in support of a general theory of agreement whereby morphological agreement and the syntactic relation Agree do not track each other directly (Chung 1998, 2013, 2014; Polinsky 2016; Sigurðsson 2004). Instead, there are cases of syntactic Agree that are not ultimately realized by morphological agreement, and there are instances of morphological agreement that are not (directly, at least) tied to a syntactic Agree relation.

There are a number of puzzles for agreement exponence inside Estonian and inside Uralic not investigated here that could be interesting domains for future research. First, in the Estonian conditional, the verb agrees only optionally, as shown in (66) and (67).

$$
\begin{aligned}
& \text { mina ela-ksi-n / ela-ks } \\
& \text { I live-COND-1sG live-COND } \\
& \text { 'I would live' } \\
& \text { meie ela-ksi-me / ela-ks } \\
& \text { we live-COND-1PL live-COND } \\
& \text { 'we would live' }
\end{aligned}
$$

(Erelt et al. 2000, 282)

For example, in (66), the verb can either bear agreement with the first-person singular subject agreement (elaksin), or it can appear without agreement (elaks). This is not only part of the spoken language, but it is also acceptable in the written standard. Erelt et al. (2000) note that the forms without agreement are more common than the forms with endings in the spoken language. According to the framework laid out here, agreeing and non-agreeing

\footnotetext{
31 In truth, the language predicted by the alternative proposal is not exactly the gap, because standard negation in that proposal would be the spell-out of $\Sigma^{0}$, not $\mathrm{C}^{0}$. Thus, it predicts the presence of a special negator which nevertheless uses the standard indicative agreement. This kind of language is also not attested, and it cannot be generated by the analysis I proposed in Section 3.
} 
conditionals would both involve an Agree relationship, but it would not always be realized morphologically.

Next, when we look at other Uralic languages, there are instances of multiple agreement exponence outside of imperatives. For example, in standard Finnish, the form known as the past participle inflects for number. ${ }^{32}$ This is true in both auxiliary constructions and negative constructions, where the past participle is used as a past indicative connegative form.

$$
\begin{aligned}
& \text { Lapset o-vat luke-neet tämän kirjan. } \\
& \text { children be-3PL read-PST.PCPL.PL this book } \\
& \text { 'The children have read this book.' }
\end{aligned}
$$

(Holmberg et al. 1993, 200)
Lapset ei-vät ol-leet
luke-neet
tätä kirjaa.

children NEG-3PL be-PST.PCPL.PL read-PST.PCPL.PL this book

'The children had not read this book.'

(Holmberg et al. 1993, 200)

In (68), we see the past participle lukeneet 'read' in an auxiliary construction. In (69), there are two past participles: one that emerges as a result of the auxiliary, the other because of negation. In each case, the participle reflects the number of the subject: plural -neet as opposed to singular - nut. It is worth considering whether these forms could be amenable to the kind of analysis investigated here.

Outside of Finnic, there are languages with indicative connegatives that agree with the subject. For example, in Komi, the indicative connegative verb inflects in the plural.

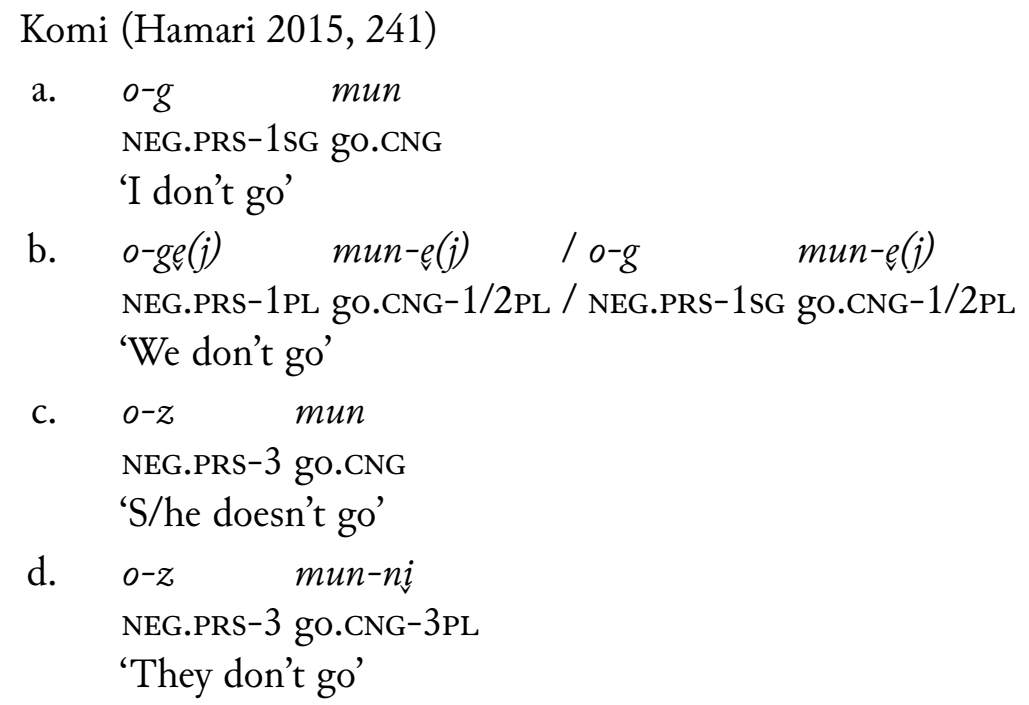

The connegative verb clearly expresses number: compare first-person singular (70a) with plural (70b). In the first- and second-person plural, plurality can also optionally be reflected on negation, giving this the appearance of multiple exponence. This is certainly another domain that could raise interesting questions for the interaction between the syntax and morphology of agreement. ${ }^{33}$

\footnotetext{
32 Holmberg et al. (1993) note that part participles do not inflect in most spoken varieties of the language. In these varieties, the singular form -nut is always used.

33 Udmurt exhibits a very similar pattern to the Komi pattern in the present tense (Edygarova 2015: 267). It also exhibits a similar but simpler pattern in the future and 1st preterite, where the connegative varies
} 
As I have mentioned, it is well-known that negation and imperativity are in some sense difficult to express in combination (van der Auwera et al. 2013). However, some languages express negated imperatives with morphosyntactic ease, suggesting this is only a tendency, not a universal. These languages make up $22.8 \%$ of the languages in the sample provided by van der Auwera et al. (2013). When the incompatibility of negation and imperativity manifests, its effects do not always have the same appearance. For example, some languages use a standard negation word combined with a non-imperative verbal form (e.g., Italian, Zanuttini 1994, 1997), others may use a special negation word but a normal imperative (like Estonian), and others may use both simultaneously. The analysis proposed here holds that negation and imperativity are in fact fully syntactically compatible in Estonian, but this is obscured by their surface forms. It is thus worth investigating other cases of apparent incompatibility to see if the incompatibility is deeply ingrained in the grammar of the language or, as I have argued for Estonian, a surface morphological effect.

\section{References}

Arregi, Karlos and Andrew Nevins (2012). Morphotactics: Basque auxiliaries and the structure of spellout. Dordrecht: Springer.

Baker, Mark and Willie Udo Willie (2010). "Agreement in Ibibio: From every head to every head". Syntax 13.2, 99-132.

Bjorkman, Bronwyn and Hedde Zeijlstra (2015). Upward Agree is superior. Presented the 33rd West Coast Conference on Formal Linguistics (WCCFL 33).

Blevins, James P. (2007). “Conjugation classes in Estonian”. Linguistica Uralica XLIII, 250-267.

Blokland, Rogier and Nobufumi Inaba (2015). "Negation in South Saami”. In: Negation in Uralic Languages. Ed. by Miestamo, Matti, Tamm, Anne, and Wagner-Nagy, Beáta. Amsterdam/Philadelphia: John Benjamins Publishing Company, 377-398.

Brattico, Pauli and Saara Huhmarniemi (2006). "Finnish negation, the EPP feature and the valuation theory of morphosyntax". Nordic Journal of Linguistics 29 (1), 5-44.

Brattico, Pauli, Saara Huhmarniemi, Jukka Purma, and Anne Vainikka (2014). "The structure of Finnish CP and feature inheritance". Finno-Ugric Languages and Linguistics 2 (2), 66-109.

Carstens, Vicki (2001). "Multiple agreement and case deletion: Against $\phi$-incompleteness". Syntax 4.3, 147-163.

Chomsky, Noam (1995). The minimalist program. Cambridge, MA: MIT press.

Chomsky, Noam (2000). "Minimalist inquiries: The framework". In: Step by step: Essays on minimalism in bonor of Howard Lasnik. Ed. by Martin, Roger, Michaels, David, and Uriagereka, Juan. Cambridge, MA: MIT Press, 89-156.

Chomsky, Noam (2001). "Derivation by Phase". In: Ken Hale: A Life in Language. Ed. by Kenstowicz, Michael. Cambridge, MA: MIT Press, 1-52.

Chung, Sandra (1998). The design of agreement: Evidence from Chamorro. Chicago: University of Chicago Press.

only for number but not for person. Another similar but simpler pattern exists in Western Mari, where the indicative connegative bears an additional suffix only in the third-person plural (Saarinen 2015: 330). 
Chung, Sandra (2013). “The syntactic relations behind agreement”. In: Diagnosing Syntax. Ed. by Cheng, Lisa Lai-Shen and Corver, Norbert. Oxford: Oxford University Press.

Chung, Sandra (2014). “On reaching agreement late”. In: CLS 48, Volume 1. Ed. by Beltrama, Andrea, Chatzikonstantinou, Tasos, Lee, Jackson L., Pham, Mike, and Rak, Diane. Chicago: Chicago Linguistic Society, 169-190.

Corbett, Greville (1991). Gender. Cambridge: CUP.

den Dikken, Marcel (2006). “Agreement”. In: Encyclopedia of Cognitive Science.

Edygarova, Svetlana (2015). "Negation in Udmurt". In: Negation in Uralic Languages. Ed. by Miestamo, Matti, Tamm, Anne, and Wagner-Nagy, Beáta. Amsterdam/Philadelphia: John Benjamins Publishing Company, 265-291.

Embick, David (2010). Localism versus globalism in morphology and phonology. Cambridge, MA: MIT Press.

Erelt, Mati, ed. (2003). Estonian language. Tallinn: Estonian Academy Publishers.

Erelt, Mati, Reet Kasik, Helle Metslang, Henno Rajandi, Kristiina Ross, Henn Saari, Kaja Tael, and Silvi Vare (1993). Eesti Keele Grammatika II: Süntaks; Lisa: Kiri [Estonian Grammar II: Syntax; Appendix: Written Language]. Tallinn, Estonia: Eest Teaduste Akadeemia Keele ja Kirjanduse Instituut.

Erelt, Mati, Tiiu Erelt, and Kristiina Ross (2000). Eesti keele käsiraamat [Estonian language handbook]. Tallinn: Eesti keele sihtasutus.

Feist, Timothy (2010). “A Grammar of Skolt Saami”. PhD thesis. University of Manchester.

Grimshaw, Jane (1991/2005). Words and structure. CSLI Publications.

Halle, M. (1990). "An approach to morphology". In: Proceedings of NELS 20. University of Massachusetts, Amherst: GLSA, 150-184.

Halle, Morris (1997). "Distributed Morphology: Impoverishment and Fission”. MITWPL 30, 425-449.

Halle, Morris and Alec Marantz (1993). "Distributed Morphology and the Pieces of Inflection". In: The View from Building 20: Essays in Linguistics in Honor of Sylvain Bromberger. Ed. by Hale, K. and Keyser, S. J. Cambridge, MA: MIT Press, 111176.

Hamari, Arja (2015). "Negation in Komi”. In: Negation in Uralic Languages. Ed. by Miestamo, Matti, Tamm, Anne, and Wagner-Nagy, Beáta. Amsterdam/Philadelphia: John Benjamins Publishing Company, 239-263.

Hamari, Arja and Niina Aasmäe (2015). "Negation in Erzya”. In: Negation in Uralic Languages. Ed. by Miestamo, Matti, Tamm, Anne, and Wagner-Nagy, Beáta. Amsterdam/Philadelphia: John Benjamins Publishing Company, 293-324.

Han, Chung-Hye (1999). "Cross-linguistic variation in the compatibility of negation and imperatives". In: Proceedings of West Coast Conference in Formal Linguistics. Vol. 17, $265-279$.

Hankamer, Jorge and Line Mikkelsen (2005). "When movement must be blocked: A reply to Embick and Noyer". Linguistic Inquiry 36.1, 85-125.

Harley, Heidi and Rolf Noyer (1999). "State-of-the-article: Distributed Morphology". GLOT international 4 (4), 3-9.

Harley, Heidi and Elizabeth Ritter (2002). "Person and number in pronouns: A featuregeometric analysis”. Language 78.3, 482-526. 
Henderson, Brent (2006). "Multiple agreement and inversion in Bantu". Syntax 9.3, 275289.

Holmberg, Anders and Urpo Nikanne (2002). "Expletives, subjects, and topics in Finnish". In: Subjects, Expletives, and the EPP. Ed. by Svenonius, Peter. Oxford: Oxford University Press, 71-105.

Holmberg, Anders, Urpo Nikanne, Irmeli Oraviita, Hannu Reime, and Trond Trosterud (1993). "The structure of INFL and the finite clause in Finnish". In: Case and other functional categories in Finnish syntax. Ed. by Holmberg, A. and Nikanne, U. Berlin: Mouton de Gruyter, 177-206.

Huhmarniemi, Saara (2012). "Finnish A'-movement: Edges and islands". PhD thesis. University of Helsinki.

Kalin, Laura and Coppe van Urk (2015). “Aspect splits without ergativity”. Natural Language \& Linguistic Theory 33.2, 659-702.

Keine, Stefan (2010). Case and agreement from fringe to core: A minimalist approach. Linguistische Arbeite. Berlin: Walter de Gruyter.

Keine, Stefan and Gereon Müller (2014). "Differential argument encoding by impoverishment”. In: Scales and Hierarcbies. Ed. by Bornkessel-Schlesewsky, I., Malchukov, A., and Richards, M. Trends in Linguistics. Berlin: Mouton de Gruyter, 75-130.

Kiparsky, Paul (2001). "Structural case in Finnish”. Lingua 111.4, 315-376.

Koskinen, Päivi (1998). "Features and categories: Non-finite constructions in Finnish". $\mathrm{PhD}$ thesis. University of Toronto.

Kramer, Ruth (2009). "Definite markers, phi-features, and agreement: A morphosyntactic investigation of the Amharic DP”. PhD thesis. University of California, Santa Cruz.

Kramer, Ruth (2010). "The Amharic definite marker and the syntax-morphology interface". Syntax 13, 196-240.

Kramer, Ruth (2015). The morphosyntax of gender: evidence from Ambaric. Oxford: Oxford University Press.

Laka, Itziar (1990). "Negation in syntax: On the nature of functional categories and projections". PhD thesis. Massachusetts Institute of Technology.

Merchant, Jason (2015). "How much context is enough? Two cases of span-conditioned stem allomorphy”. Linguistic Inquiry 46 (2), 273-303.

Metslang, Helle, Karl Pajusalu, and Tiit-Rein Viitso (2015). "Negation in Livonian". In: Negation in Uralic Languages. Ed. by Miestamo, Matti, Tamm, Anne, and WagnerNagy, Beáta. Amsterdam/Philadelphia: John Benjamins Publishing Company, 433456.

Miestamo, Matti (2005). Standard negation: the negation of declarative verbal main clauses in a typological perspective. Berlin: Mouton de Gruyter.

Miestamo, Matti and Eino Koponen (2015). "Negation in Skolt Saami”. In: Negation in Uralic Languages. Ed. by Miestamo, Matti, Tamm, Anne, and Wagner-Nagy, Beáta. Amsterdam/Philadelphia: John Benjamins Publishing Company, 353-376.

Miestamo, Matti, Anne Tamm, and Beáta Wagner-Nagy, eds. (2015). Negation in Uralic languages. Amsterdam/Philadelphia: John Benjamins Publishing Company.

Miljan, Merilin and Ronnie Cann (2013). "Rethinking case marking and case alternation in Estonian”. Nordic Journal of Linguistics 36 (03), 333-379. 
Mitchell, Erika (1991). "Evidence from Finnish for Pollock's theory of IP". Linguistic Inquiry 22 (2).

Mitchell, Erika (2006). "The morpho-syntax of negation and the positions of NegP in the Finno-Ugric languages”. Lingua 116.3, 228-244.

Müller, Gereon (2007). "Extended exponence by enrichment: argument encoding in German, Archi, and Timucua”. In: Proceedings of the 30th Annual Penn Linguistics Colloquium. Ed. by Scheffler, Tatjana, Tauberer, Joshua, Eilam, Aviad, and Mayol, Laia, 253-266.

Mus, Nikolett (2015). "Negation in Tundra Nenets". In: Negation in Uralic Languages. Ed. by Miestamo, Matti, Tamm, Anne, and Wagner-Nagy, Beáta. Amsterdam/Philadelphia: John Benjamins Publishing Company, 75-102.

Nelson, Diane (1998). Grammatical case assignment in Finnish. New York \& London: Garland.

Nickel, Klaus Peter (1990). Samisk grammatikk. Oslo: Universitetforlaget.

Norris, Mark (2014). "A theory of Nominal Concord”. PhD thesis. University of California, Santa Cruz.

Polinsky, Maria (2016). "Agreement in Archi from a minimalist perspective". In: Arcbi: complexities of agreement in a cross-theoretical perspective. Ed. by Bond, Oliver, Corbett, Greville, Chumakina, Marina, and Brown, Dunstan. Oxford: Oxford University Press.

Preminger, Omer (2014). Agreement and its failures. Vol. 68. Linguistic Inquiry Monographs. Cambridge, MA: MIT Press.

Preminger, Omer and Maria Polinsky (2015). Upwards and onwards: On the direction of valuation in $\phi$-feature agreement. Handout of a talk presented at New York University, April 25, 2015.

Rivero, Maria Luisa and Arhonto Terzi (1995). "Imperatives, V-movement and logical mood”. Journal of Linguistics 31.02, 301-332.

Rozhanskiy, Fedor and Elena Markus (2015). "Negation in contemporary Votic”. In: Negation in Uralic Languages. Ed. by Miestamo, Matti, Tamm, Anne, and Wagner-Nagy, Beáta. Amsterdam/Philadelphia: John Benjamins Publishing Company, 487-515.

Saarinen, Sirkka (2015). "Negation in Mari”. In: Negation in Uralic Languages. Ed. by Miestamo, Matti, Tamm, Anne, and Wagner-Nagy, Beáta. Amsterdam/Philadelphia: John Benjamins Publishing Company, 325-352.

Schoorlemmer, Erik and Tanja Temmerman (2012). "Head movement as a PF-phenomenon: Evidence from identity under ellipsis". In: Proceedings of the 29th West Coast Conference on Formal Linguistics. Ed. by Choi, Jaehoon, Hogue, E. Alan, Punske, Jeffrey, Tat, Deniz, Schertz, Jessamyn, and Trueman, Alex. Somerville, MA: Cascadilla Proceedings Project, 232-240.

Siegl, Florian (2015). "Negation in Forest Enets". In: Negation in Uralic Languages. Ed. by Miestamo, Matti, Tamm, Anne, and Wagner-Nagy, Beáta. Amsterdam/Philadelphia: John Benjamins Publishing Company, 45-73.

Sigurðsson, Halldór Ármann (2004). "Agree in syntax, agreement in signs”. Working Papers in Scandinavian Syntax 74, 1-42.

Sulkala, Helena and Merja Karjalainen (1992). Finnish. London and New York, NY: Routledge. 
Svenonius, Peter (2012). Spanning. Ms., CASTL, University of Tromsø.

Tamm, Anne (2015). "Negation in Estonian". In: Negation in Uralic Languages. Ed. by Miestamo, Matti, Tamm, Anne, and Wagner-Nagy, Beáta. Amsterdam/Philadelphia: John Benjamins Publishing Company, 399-431.

Toivonen, Ida and Diane Nelson, eds. (2007). Saami linguistics. Amsterdam: John Benjamins.

van der Auwera, Johan, Ludo Lejeune, and Valentin Goussev (2013). "The prohibitive”. In: The World Atlas of Language Structures Online. Ed. by Dryer, Matthew S. and Haspelmath, Martin. Leipzig: Max Planck Institute for Evolutionary Anthropology. Chap. 71. URL: http://wals.info/chapter/71.

Wilbur, Joshua (2014). A grammar of Pite Saami. Berlin: Language Science Press.

Zanuttini, Raffaella (1994). "Speculations on negative imperatives". Rivista di Linguistica 6 (1), 67-89.

Zanuttini, Raffaella (1997). Negation and clausal structure. Oxford: Oxford University Press. Zanuttini, Raffaella (2008). "Encoding the addressee in the syntax: evidence from english imperative subjects”. Natural Language \& Linguistic Theory 26.1, 185-218.

Zanuttini, Raffaella, Miok Pak, and Paul Portner (2012). "A syntactic analysis of interpretive restrictions on imperative, promissive, and exhortative subjects”. Natural Language \& Linguistic Theory 30.4, 1231-1274.

Mark Norris

University of Oklahoma

mark-norris@ou.edu 